\title{
Fibers Obtained from Invasive Alien Plant Species as a Base Material for Paper Production
}

\author{
Marica Starešinič (D), Bojana Boh Podgornik, Dejana Javoršek, Mirjam Leskovšek (D) and Klemen Možina *(D) \\ Department for Textile, Graphic Arts and Design, Faculty of Natural Sciences and Engineering, \\ University of Ljubljana, Snežniška 5, SI-1000 Ljubljana, Slovenia; marica.staresinic@ntf.uni-lj.si (M.S.); \\ bojana.boh@ntf.uni-lj.si (B.B.P.); dejana.javorsek@ntf.uni-lj.si (D.J.); mirjam.leskovsek@ntf.uni-lj.si (M.L.) \\ * Correspondence: klemen.mozina@ntf.uni-lj.si; Tel.: +386-1-200-32-99
}

Citation: Starešinič, M.;

Boh Podgornik, B.; Javoršek, D.; Leskovšek, M.; Možina, K. Fibers Obtained from Invasive Alien Plant Species as a Base Material for Paper Production. Forests 2021, 12, 527. https://doi.org/10.3390/f12050527

Academic Editor: Geoffrey Daniel

Received: 24 March 2021

Accepted: 19 April 2021

Published: 24 April 2021

Publisher's Note: MDPI stays neutral with regard to jurisdictional claims in published maps and institutional affiliations.

Copyright: (c) 2021 by the authors. Licensee MDPI, Basel, Switzerland. This article is an open access article distributed under the terms and conditions of the Creative Commons Attribution (CC BY) license (https:// creativecommons.org/licenses/by/ $4.0 /)$.

\begin{abstract}
Invasive alien plant species (IAPS) are one of the biggest challenges in European ecosystems, displacing local vegetation, destroying agricultural land, and causing billions of dollars of damage to the European economy every year. Many of them are removed daily and mainly burned. In this work, we investigated the possibilities of using plants as feedstock for paper production. Papers made from three invasive alien plants, i.e., Knotweed, Goldenrod, and Black locust, were studied and compared with commercial office paper. The study included testing of: (1) structural propertiesbasic physical properties, grammage, thickness, density and specific volume, moisture content, and ash content; (2) physical and dynamic mechanical properties-tensile strength, Clark stiffness, viscoelastic properties; (3) colorimetric properties of prints; (4) effect of UV light on ageing; and (5) study of cellulose fiber structure and morphology by microscopy. The results suggested that the paper produced can be used as commercial office paper, considering that the paper is slightly dyed. Such papers can also be used for special purposes that present a natural style and connection to nature. The papers produced can also be used for printing documents that are meant to be kept.
\end{abstract}

Keywords: cellulose; paper; invasive alien plants; Knotweeds; Goldenrods; Black Locust; scanning electron microscopy; dynamic mechanical analysis

\section{Introduction}

\subsection{Background}

Invasive alien plant species (IAPS) are non-native plants that have been introduced by human activities. IAPS have been transported from outside their natural ecological range to new habitats where they survive, reproduce, and spread rapidly without human assistance. IAPS are one of the greatest challenges in European ecosystems. Their spread disturbs the balance of natural ecosystems in many ways. By competing with each other, transmitting diseases, altering soil and light conditions, and reshaping the functioning of the whole ecosystem, they pose a major threat to native species richness and habitat biodiversity. They displace native vegetation, destroy agricultural land, and cause billions of dollars of damage to the European economy every year. Therefore, they are considered a disturbance with negative impacts on native species and ecosystems [1]. Many of them are removed daily and mainly burned.

APPLAUSE (IAPS from harmful to useful with citizens' led activities) is the international research project in Ljubljana Slovenia to develop a new system to combat IAPS. Ljubljana has made progress in developing its circular model for IAPS management. The reorientation from linear to circular will not only have a significant impact on individual business models in the future, but will change the way we think, our economic and social systems. If we learn to consume and consume less, and also implement the principles of the sharing economy, we and our environment will be the winners [2]. This new system combines fieldwork with IAPS detection through satellite and aerial data. The goal is that combining the two will make the entire process much more efficient. To further facilitate 
this process, APPLAUSE is developing a set of digital tools to support IAPS identification and geolocation, while professionals, as well as citizens, are "out in the field" [3].

In Slovenia there are no special landfills for IAPS, so all collected biomass is taken to incinerators. Ljubljana, as a "zero waste city", has recognized the potential to establish a systematic participatory model that uses collected biomass to develop new sustainable products. New green technologies have been introduced, such as: pilot enzymatic processing of IAPS fibers instead of chemicals, reuse of waste generated from primary wood processing and papermaking, conversion of residues into liquid wood, development of biotechnological biorefinery device for caustic conversion, the production of novel 3D bio composites, the production of dyes, the production of colored coatings from IAPS, the development of a model dye-based solar cell from IAPS, and the development of homemade formulations against plant-damaging organisms. One of the biggest challenges will be to develop successful and trustworthy circular economy models, find new uses for all parts of the collected IAPS, and upcycle the residual materials [4]. Information and communication technology (ICT) will be used to target audiences and produce open data, new knowledge, and new services, such as IAPS monitoring with data from aerial orthophotos and Sentinel-2 satellites.

The APPLAUSE project began with plant identification and location. For Japanese knotweed detection, satellite imagery was used to determine the location of plants. Remote sensing, as satellites are called, is already being used in forestry, agriculture, and ecology because it is a less expensive technique compared to field reconnaissance methods (Figure 1).

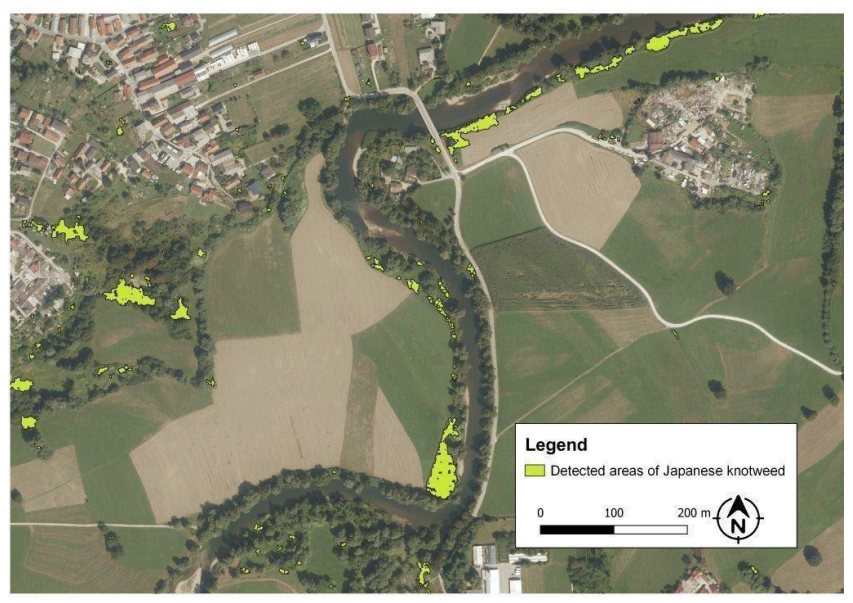

Figure 1. Aerial image of Ljubljana location where Japanese knotweed was detected [5].

Preliminary research by Lavrič [6] has shown that the invasive Japanese knotweed could be used as a cheap local raw material in the paper industry, but in order to achieve good printability properties of the paper, mainly the fiber processing needs to be improved. Kim et al., isolated cellulose nanofibers from pulps of a tall goldenrod (Solidago altissima L.), an invasive plant in Korea, using electron beam irradiation [7]. Nanofibers were characterized, and paper samples prepared. Papers produced from more finely separated fibers, generated by using higher doses of electron beam irradiation, had enhanced UV-vis transmittance, lower thermal stability, higher char yield, and increased tensile strengths. In a study by Saikia [8], the fast-growing annual plants Hibiscus sabdariffa L., Crotalaria juncea L., Tephrosia candida (Roxb.) DC., and Hibiscus cannabinus L., and a reed species were investigated in the laboratory for their properties for pulp and paper production, and the results suggested that the plant species studied would be ideal sources of raw material for the pulp and paper industry. In the project APPLAUSE, seven IAPS were used for pilot paper production, namely Ailanthus, Rhus, Black locust, Canadian goldenrod, Rudbeckia, Japanese knotweed, and Bohemian knotweed [9]. The basic chemical and mechanical 
properties of the manufactured products were tested. The mechanical properties, such as tensile index, breaking length, tear index, and bursting strength of the paper produced from IAPS were similar but differed from batch to batch depending on the additives used.

In the databases and literature analyzed, we did not find any other studies on the IAPS used as a base material for paper production, so we decided to further investigate and evaluate papers made from three groups of IAPS-Knotweed, Goldenrod, and Black locust.

\subsection{Description and Properties of the IAPS Used in the Study}

\subsubsection{Knotweeds (Fallopia japonica, Fallopia sachalinensis, and Fallopia $\times$ bohemica)}

The knotweed family (Polygonaceae), belonging to the order Polygonales, includes about 40 genera. The taxonomy and nomenclature of the species has changed several times [10]. The three invasive Fallopia species in Slovenia [11], namely Fallopia japonica (Houtt.) Ronse Decr. (synonyms Reynoutria japonica Houtt., Polygonum cuspidatum Siebold \& Zucc.), Fallopia sachalinensis (F.Schmidt) Ronse Decr., and Fallopia $\times$ bohemica (Chrtek \& Chrtková) J.P.Bailey (a hybrid between Fallopia japonica and Fallopia sachalinensis) are tall herbaceous perennials with roots reaching 1-2 m deep and rhizomes spreading laterally. Phenotypic variability is characteristic of all three species, especially the highly polymorphic Fallopia japonica. However, the three species differ in a combination of characters (Table 1).

Table 1. Morphological macroscopic differences between Fallopia japonica, Fallopia sachalinensis, and Fallopia $\times$ bohemica $[10,11]$.

\begin{tabular}{|c|c|c|c|}
\hline \multirow{2}{*}{ Height } & Fallopia japonica & Fallopia sachalinensis & Fallopia $\times$ bohemica \\
\hline & $1.5-2.0 \mathrm{~m}$ & $2.5-3.5 \mathrm{~m}$ & $2.0-3.5 \mathrm{~m}$ \\
\hline Leaves & $\begin{array}{l}\text { length } 5-15 \mathrm{~cm} \text {, width } \\
4-10 \mathrm{~cm} \text {, leaf base truncated, } \\
\text { underside appears glabrous }\end{array}$ & $\begin{array}{l}\text { length } 15-35 \mathrm{~cm} \text {, width } \\
10-20 \mathrm{~cm} \text {, leaf base distinctly } \\
\text { heart-shaped, underside } \\
1 \mathrm{~mm} \text { long trichomes }\end{array}$ & $\begin{array}{l}\text { length } 10-23 \mathrm{~cm} \text {, width } \\
9-20 \mathrm{~cm} \text {, leaf base at least } \\
\text { slightly heart-shaped, } \\
\text { underside } 0.5 \mathrm{~mm} \text { long } \\
\text { trichomes }\end{array}$ \\
\hline Flowers & $\begin{array}{l}\text { 2-4 in one cluster, flowering } \\
\text { July-September }\end{array}$ & $\begin{array}{l}\text { 4-7 in one cluster, flowering } \\
\text { July-September }\end{array}$ & $\begin{array}{c}\text { 3-5 in one cluster, flowering } \\
\text { July-October }\end{array}$ \\
\hline Photo of the leaf & & 7 & \\
\hline
\end{tabular}

The original range of Fallopia japonica, is in East-Asia, including Japan, China, Russia, Korea, and Taiwan, while Fallopia sachalinensis, is native to Russia and Japan. Fallopia japonica, was first introduced as an interesting plant in a Dutch botanical garden in 1823 [10]. Both species were later cultivated in several places in Europe as ornamental plants, as high-yielding green fodder for livestock and wildlife, and as honeybee grazing plants with autumn flowers. Over the years, they spread in Europe from North America and became a serious threat to natural ecosystems and their biodiversity with their very invasive and almost completely homogeneous populations [12]. Their control has become very difficult, so much so that they are listed among the 100 most invasive alien species in the world.

However, in Japan and China, Knotweed is known as a traditional edible and medicinal plant from which several medicinal compounds have been isolated and identified, including flavonoids, quinones, stilbenes, counmarines, ligans, and others [13-16]. Fal- 
lopia japonica, is a rich source of resveratrol, a well-known polyphenol antioxidant with potent biological activity $[17,18]$. The extract of rhizomes containing stilbenes (resveratrol) and hydroxyanthraquinones (emodin) exhibits potent antibacterial properties [11]. Extracts from rhizomes can be used for dyeing textiles and for antimicrobial effects [19].

\subsubsection{Goldenrods (Solidago canadensis L. and Solidago gigantea Aiton)}

Solidago canadensis, i.e., Canadian goldenrod and Solidago gigantea, i.e., Giant goldenrod (Asteraceae) are rhizomatous perennial plants that originated in northern America and were introduced to Europe and Asia. Both are also found in Slovenia. They are invasive and often occur in dense monospecific stands due to their high growth rate, ability to spread locally via rhizomes, production of large numbers of wind-borne seeds that germinate readily on a wide range of soils, and allelopathic interactions that inhibit the germination and growth of seedlings of other species [20-23].

The species Solidago Canadensis, and Solidago gigantea, have similar habit and grow 30-280 cm tall. The stems are unbranched except in the inflorescence. The leaves are simple and alternate, stalkless, three-nerved, the margins usually serrate. Inflorescences form broad pyramidal panicles with recurved branches and a central axis. The ray florets are yellow, female, and fertile, the disc florets are bisexual and fertile. The main flowering period is between mid August and late September. Both species occur in the same habitat types, such as disturbed areas, railway and roadside verges, riverbanks, urban and peri-urban areas, cultivated agricultural land, plantations and orchards, woodlands, and meadows $[24,25]$. Due to macroscopic similarities, variability, and difficulty in species determination, the name Solidago, i.e., goldenrod, has often been used as a common name for both Solidago canadensis, and Solidago gigantea. For example, the European Pharmacopoeia accepts the two equivalent species, Solidago canadensis, and Solidago gigantea, as goldenrod, i.e., Solidaginis herba [26].

However, the two species can be recognized and identified by some specific morphological and macroscopic characteristics, which are summarized in Table 2.

Table 2. Morphological macroscopic differences between Solidago canadensis and Solidago gigantea [19,20,24,25].

\begin{tabular}{|c|c|c|}
\hline & Solidago canadensis & Solidago gigantea \\
\hline Stems & $\begin{array}{l}\text { Hair on the upper third of the stem } \\
\text { (distinctly pubescent at the summit below } \\
\text { the inflorescence) }\end{array}$ & $\begin{array}{l}\text { Stem is glabrous, smooth, not pubescent } \\
\text { below the inflorescence (may be weakly } \\
\text { hairy in the inflorescence only); may have } \\
\text { a purplish cast and a white, waxy bloom }\end{array}$ \\
\hline \multicolumn{3}{|c|}{ Photo of the stem } \\
\hline Flowers & $\begin{array}{c}\text { Smaller flowers, with a pyramidal panicle } \\
\text { (the corolla is } 2.4-2.8 \mathrm{~mm} \text { long; achenes } \\
\text { are pubescent, } 0.9-1.2 \mathrm{~mm} \text { long, with a } \\
\text { pappus of } 2.0-2.5 \mathrm{~mm} \text { ) }\end{array}$ & $\begin{array}{l}\text { Larger flowers with a more sparsely } \\
\text { packed panicle, denser inflorescence } \\
\text { architecture (the capitula are } 3-5 \mathrm{~mm} \\
\text { long; achenes are pubescent, } 1-2 \mathrm{~mm} \\
\text { long, with a pappus of } 1 \mathrm{~mm} \text { long) }\end{array}$ \\
\hline
\end{tabular}

In addition to differences in plant morphology, quantitative and qualitative differences in phytochemical profiles, and bioactivities between Solidago canadensis, and Solidago gigantea L. [25], and between the European native species Solidago virgaurea, compared to invasive alien species Solidargo canadensis, and Solidargo gigantea, both in the number and amount of chemical compounds, as well as in their antimicrobial, antimutagenic, and 
antioxidant activities $[27,28]$. While the generally accepted trends and strategies regarding invasive plant species aim at limiting or eliminating the invaders, some research groups following the principles of bioeconomics are investigating potential uses of invasive Solidago, species and trying to convert waste into valuable products. According to the review paper by Zihare and Blumberga, Solidargo canadensis, contains components of interest in all parts of the plant: essential oils with antimicrobial and antioxidant properties, natural dyes for textile dyeing, extracted substances with algicidal, antimicrobial and antioxidant properties, stems for cellulose blends, and plant residues for the production of heating pellets and methane biofuel [29].

\subsubsection{Black Locust (Robinia pseudoacacia L.)}

Due to the conflict between multiple human uses and negative environmental impacts, Robinia pseudoacacia, is considered controversial, i.e., an intentionally planted tree that is also an invasive species in Europe [30]. It was introduced to Europe in the early 17th century from North America and has become one of the most commonly planted woody species, used as an ornamental tree, as well as for the production of water- and rot-resistant timber, firewood, leaf fodder for animals, nectar source for bees, and to improve and control erosion [31-33]. It is a drought-resistant tree that can grow on dry, rocky sites, and fixes atmospheric nitrogen in symbiosis with Rhizobium. Therefore, it has become a species for marginal lands where soil improvement is sought in addition to economic gain [34,35], as well as an invasive plant that threatens natural habitats by reducing local biodiversity [36-38]. Chemical studies revealed the presence of flavonoids [32], condensed tannins [39], immunopotentiating polysaccharides [40], and an essential oil from the flowers with antimicrobial activity against selected foodborne pathogens [41].

\subsubsection{Aims and Scope of the Study}

The main objective of the study was to evaluate papers made from three groups of IAPS, i.e., Knotweeds, Goldenrods, and Black locust, and compare them with the commercially available office paper. The detailed objectives were to study and compare the papers in terms of: (1) structural properties, i.e., surface morphology, grammage, thickness, density and specific volume, moisture content, and ash content; (2) physical and dynamic mechanical properties, i.e., tensile strength, Clark stiffness, storage modulus, and relaxation transition temperature; (3) colorimetric properties of prints; (4) influence of UV light on paper ageing.

The following research hypotheses $(\mathrm{H})$ were formulated and evaluated:

Hypothesis 1. Papers made from cellulose fibers from IAPS are comparable to papers made from conventional wood cellulose fibers.

Hypothesis 2. Papers made from IAPS cellulose fibers exhibit a higher degree of anisotropy.

Hypothesis 3. The elasticity of papers made from IAPS is significantly different from commercial office paper.

Hypothesis 4. UV exposure deteriorates the elasticity of paper made from IAPS, as well as that of commercial office paper.

Hypothesis 5. Commercial office paper has the highest contrast of the area printed with black.

Hypothesis 6. Exposure of the paper with a UV printer does not affect the paper itself.

Hypothesis 7. The surface morphology of papers from IAPS are similar to office paper.

Hypothesis 8. The use of papers from IAPS for printing is the same as that of office paper. 


\section{Materials and Methods}

\subsection{Paper Samples}

A total of four paper samples were included in the study, i.e., papers from three IAPS, i.e., Knotweeds (KW), Black locust (BL), and Goldenrods (GR), and a commercial office paper (COP). The properties of papers from IAPS were compared with those of a widely used commercial office paper used in domestic environment and for printing documents intended for storage. All papers were produced by machine, i.e., IAPS papers were produced on an Andritz paper machine (Andritz AG, Graz, Austria, located in Pulp and Paper Institute, Ljubljana, Slovenia), while commercial office paper used spruce, pine, eucalyptus, and beech cellulose fibers, and paper was produced on a Paper Machine 4 (PM4) (Voith Paper Krieger, Mönchengladbach, Germany, located in Radeče papir Nova paper mill, Radeče, Slovenia). The paper samples used in this study were coded as shown in Table 3.

Table 3. Paper samples.

\begin{tabular}{cc}
\hline Sample & Paper Sample Made from \\
\hline KW & Knotweeds \\
BL & Black locust \\
GR & Goldenrods \\
COP & Commercial office paper \\
\hline
\end{tabular}

Table 4 shows the chemical analysis of the paper produced from IAPS, for which $300 \mathrm{~kg}$ of air-dried biomass was included in one batch, with only the stems, excluding leaves, flowers and roots, cut into $3-5 \mathrm{~cm}$ chips [9].

Table 4. Chemical analysis of IAPS [9].

\begin{tabular}{ccccc}
\hline Sample & $\begin{array}{c}\text { Ethanol } \\
\text { Extractives [\%] }\end{array}$ & Cellulose [\%] & Hemicellulose [\%] & Lignin [\%] \\
\hline KW & 1.1 & 35.0 & 36.6 & 27.0 \\
BL & 4.7 & 41.0 & 35.0 & 22.0 \\
GR & 1.6 & 37.0 & 36.0 & 19.0 \\
\hline
\end{tabular}

\subsection{Methods}

The investigations carried out included the structural, physical, and dynamicmechanical properties of papers, as well as colorimetric measurements, UV exposure, and morphological analyses using light and scanning electron microscopy to determine the surface structure of cellulose fibers in the paper.

\subsubsection{Surface Morphology}

All samples were examined by both light microscopy and scanning electron microscopy (SEM) to determine the surface morphology of the paper produced. SEM microscope JSM 6060LV (Jeol Ltd., Tokyo, Japan) and Leica S9i (Leica Camera AG, Wetzlar, Germany) stereo microscope were used.

The scanning electron microscope [42], uses a focused beam of high-energy electrons to generate a variety of signals at the surface of solid samples. The signals resulting from electron-sample interactions provide information about the sample, including the external morphology (texture), and the crystalline structure and orientation of the materials that make up the sample. The SEM is a critical instrument with the breadth of applications in the study of in all fields that require characterization of solid materials.

Today's stereo microscopes are equipped with high numerical aperture objectives that produce high contrast images with a minimum of stray light and geometric distortion. Observation tubes accommodate high interpupillary distance eyepieces that have a field of view of up to $26 \mathrm{~mm}$, with a diopter adjustment that allows the image and graticule to 
be brought into focus simultaneously. The stereomicroscope has been used in research to inspect specimens and also to prepare specimens for SEM microscopy.

\subsubsection{Structural Properties}

In the area of basic physical properties, several methods have been chosen to divide papers into individual categories and describe their differences based on raw material composition. Basic physical paper properties include the 2- and 3-dimensional properties of paper, i.e., grammage, thickness, density, specific volume, moisture, and ash content.

Grammage, Thickness, Density and Specific Volume

Grammage has been determined in accordance with ISO 536:2019 [43]. The thickness, i.e., the 3-dimension of the paper, the perpendicular distance between the sides of the paper, and the specific volume were determined in accordance with ISO 534:2011 [44], as were the density and specific volume.

\section{Moisture Content}

Moisture content has a significant effect on how the material behaves under different climatic conditions. Therefore, the papers were exposed to the standard climate, i.e., $23{ }^{\circ} \mathrm{C}$ and 50\% RH according to ISO 287:2017 [45]. Moisture content affects grammage, mechanical strength, bending stiffness, formation, paper time (degree of degradation), and dimensional stability, calendaring, and printing.

Residue (Ash) Content

The determination of the ash residue (ash) at $525^{\circ} \mathrm{C}$ is the paper property that significantly determines the usability of the final product and was determined according to ISO 1762 [46]. The ratio between cellulose fibers and inorganic fillers has a significant influence on the physical-mechanical, as well as on the viscoelastic properties. The influence on the mentioned properties is negative with increasing amount of inorganic fillers, i.e., calcium carbonate $\left(\mathrm{CaCO}_{3}\right)$, kaolin $\left(\mathrm{Al}_{2} \mathrm{O}_{3} \times 2 \mathrm{SiO}_{2} \times 2 \mathrm{H}_{2} \mathrm{O}\right)$, and titanium dioxide $\left(\mathrm{TiO}_{2}\right)$, because the proportion of chemical bonding between individual cellulose fibers decreases.

\subsubsection{Physical and Dynamic Mechanical Properties}

The physical-mechanical properties include, first and foremost, a series of methods that describe the paper as a function of parameters that ensure an undisturbed flow of paper through the various stages of refinement and are highly dependent on the morphological properties of the cellulose fibers and the technological parameters of papermaking. As mentioned above, the relationship between cellulosic fibers and paper fillers has a noticeable influence on the behavior of the paper under physical-mechanical stress. Cellulosic fibers represent an ever-increasing cost factor, so that they are increasingly displaced, usually with inorganic fillers, in order to achieve a certain grammage, so that the measurement of physical-mechanical properties becomes one of the key factors in the evaluation and comparison of papers produced from different raw materials.

Tensile Properties

Tensile properties were measured vertically on the Instron 5567 dynamometer at a constant load increase until a $15 \mathrm{~mm}$ wide paper strip broke and at a clamping length of $180 \mathrm{~mm}$ according to ISO 1924-2 [47].

\section{Clark Stiffness}

Although Clark stiffness (CS) is not a standardized method, the measurement of bending stiffness is of great importance when it comes to the printing substrate. CS is an indirect method in which the $25 \mathrm{~mm}$ wide paper strip was subjected to a sonic pulse of $160 \mathrm{~Hz}$ using Pulse Propagation Meter PPM-5R (Lawson-Hemphill Inc., Swansea, MA, 
USA), and the measurement step was fixed at $1 \mathrm{~cm}$. The speed of sound was calculated according to Equation (1).

$$
\mathrm{C}=\frac{\Delta \mathrm{l}}{\Delta \mathrm{t}} ;[\mathrm{km} / \mathrm{s}]
$$

where:

C—sound velocity, [km/s];

$\Delta \mathrm{l}$-distance between transmitter and receiver, [cm];

$\Delta \mathrm{t}$ - time needed for the sound signal to travel between the transmitter and receiver, [ $\mu \mathrm{s}]$.

According to Equation (2), the modulus of elasticity or the Young modulus was calculated.

$$
\mathrm{E}=\mathrm{C}^{2} \times \rho ;[\mathrm{MPa}]
$$

where:

E-Young's modulus, [MPa];

$\rho$-paper density, $\left[\mathrm{kg} / \mathrm{m}^{3}\right]$.

Finally, the CS can be calculated, i.e., Equation (3):

$$
\mathrm{CS}=\frac{\mathrm{E} \times \mathrm{d}^{3}}{12} ;[\mathrm{Nmm}]
$$

where:

CS-Clark stiffness, [Nmm];

$\mathrm{d}$-paper thickness, [mm].

Offset printing is the printing process most sensitive to insufficient paper stiffness. Paper with insufficient stiffness can cause problems in the "wet" printing technique, i.e., offset printing, when handling the paper, i.e., handling. During printing, wrinkles, flaps, and jams occur on the printouts. During the bending process (printing, finishing) the outer paper layer is exposed to higher tensile forces than the inner paper core. A detailed explanation of the bending stiffness according to CS gives us detailed insights into the elasticity or extensibility of the paper core. Modulus of elasticity, especially in its variation between paper structures. A higher number of contact points between the "swollen" cellulose fibers, caused by the use of water in offset printing, contributes to an increase in the frictional force, and a decrease in the flexibility of the paper [48].

Dynamic Mechanical (Viscoelastic) Properties

Since the papermaking and end-use of pulp paper can take place over a wide range of temperatures and under different loading situations, it is important to also investigate the viscoelastic behavior of the paper. Temperature-dependent relaxation transitions in the paper structure and the indication of the elasticity of the paper are two main parameters that should always be closely considered in order to avoid structural changes at the micro level that lead to micro cracks in the paper.

The viscoelastic properties of the paper were studied and carried out using dynamic mechanical instrument DMA Q800 (TA Instruments, New Castle, DE, USA). The specimens were clamped, i.e., deformed in tensile mode and subjected to oscillatory vibration with amplitude $10 \mu \mathrm{m}$ and frequency $10 \mathrm{~Hz}$. The dimensions of the specimen were: $50 \mathrm{~mm}(\mathrm{~L}) \times 7 \mathrm{~mm}(\mathrm{~W})$. The samples were heated from $0-250{ }^{\circ} \mathrm{C}$ with the constant rate $3{ }^{\circ} \mathrm{C} / \mathrm{min}$ in a liquid nitrogen atmosphere. The following temperature-dependent quantities defining the dynamic-mechanical properties of the paper were observed: the relaxation transition temperature $(\mathrm{Tr})$, the storage modulus $\left(\mathrm{E}^{\prime}\right)$, the mechanical loss modulus $\left(\mathrm{E}^{\prime \prime}\right)$, and the damping factor $\tan \delta$.

\subsubsection{Colorimetric Measurements}

All spectrophotometric measurements were performed using the EyeOne Pro 2 spectrophotometer (X-Rite Pantone, Grand Rapids, MI, USA). CIELAB values were calculated 
using standard illuminant D50 and standard observer $2^{\circ}$. For comparison between the base paper and the base paper exposed with the UV printer, the equation DE *ab was used.

\subsubsection{UV Impact}

IAPS paper samples were aged with a xenon lamp in a Xenotest ${ }^{\circledR}$ Alpha instrument (Atlas Materail Testing Technology $\mathrm{GmbH}$, Linsengericht, Germany) according to the standard ISO $12040\left(35^{\circ} \mathrm{C}\right.$ chamber temperature, $50{ }^{\circ} \mathrm{C}$ black standard temperature, $35 \%$ relative humidity) [49]. The exposure time was $72 \mathrm{~h}$.

\subsubsection{Printing}

The papers were printed using technologies and printing inks. The UV printer Apex Jet 6090 (Apex, Shenzhen, China) [50], were used on all samples.

\section{Results and Discussion}

\subsection{Surface Morphology}

From the stereomicroscope images of the paper samples shown in Table 5, it can be seen that the papers made from IAPS are more textured and robust compared to office papers. Samples KW-GR are darker in color and single (individual) fibers can be seen compared to COL. In the printed images we can see that all papers are suitable for printing with different inks, the edges are clear, but prints on IAPS cellulose have a darker color because the papers are darker.

Table 5. Stereomicroscope images of paper samples.

\begin{tabular}{|c|c|c|c|c|}
\hline Sample & Light Microscopy & Paper with UV Print & $\begin{array}{c}\text { Paper with Water-Based } \\
\text { Print }\end{array}$ & $\begin{array}{l}\text { Paper with Organic } \\
\text { Solvent-Based Print }\end{array}$ \\
\hline KW & & & & \\
\hline BL & & & & \\
\hline GR & & & & \\
\hline $\mathrm{COP}$ & & & & \\
\hline
\end{tabular}

In Table 6, we can see SEM images showing the detailed structure of the papers. The morphological surface structure of the papers is similar for all samples from IAPS: the fibers are wider, bulkier, and thicker compared to office paper, where the fibers are thinner. Samples KW-GR also have larger fillers and show a hollower structure compared to COP. 
Table 6. SEM images of paper samples.

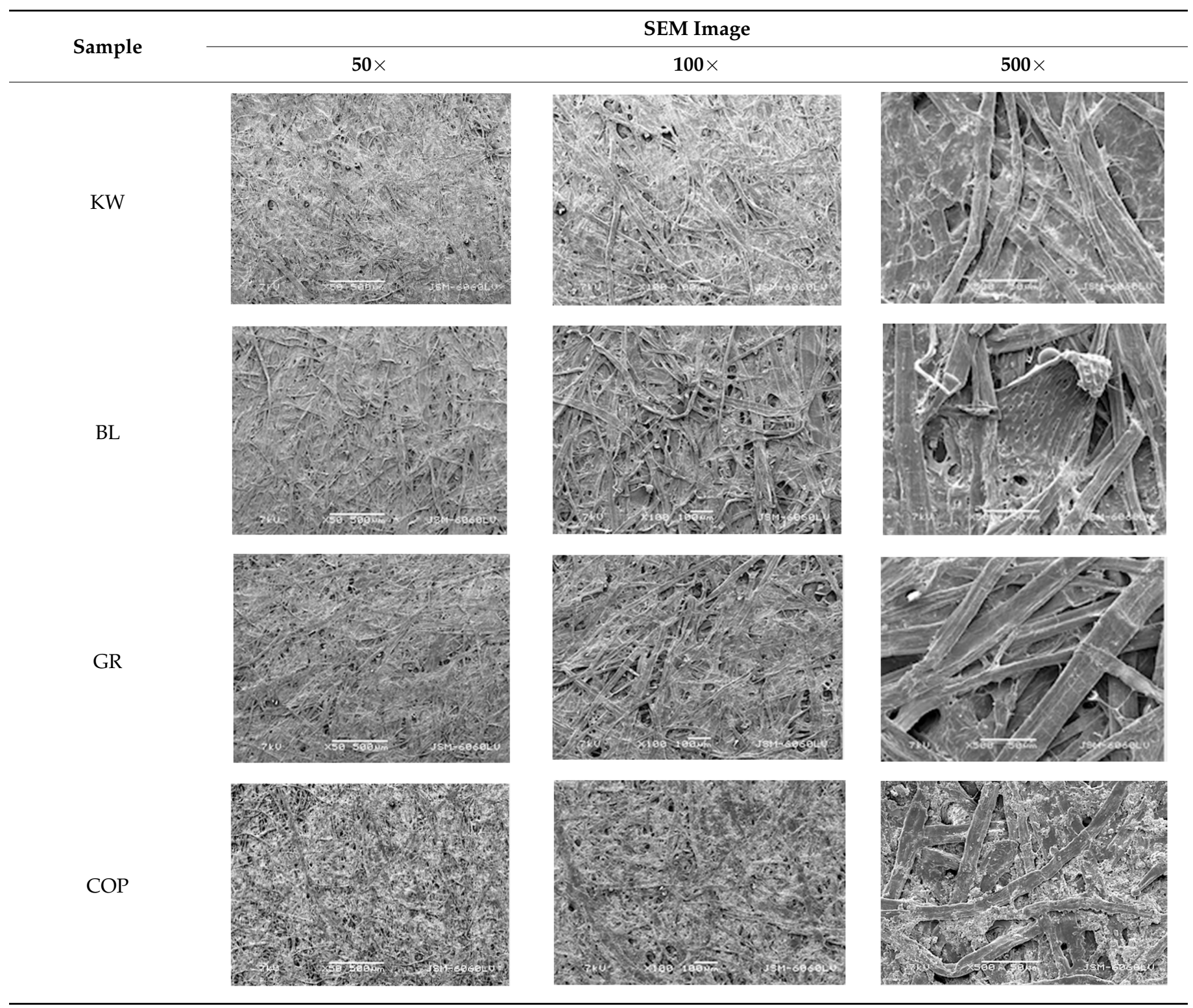

\subsection{Structural Properties}

3.2.1. Surface Morphology

For the basic physical characteristics, the grammage, thickness, specific volume, moisture, and residue (ash) content were assessed (Table 7).

Table 7. Physical properties of paper made from different cellulose fibers.

\begin{tabular}{cccccc}
\hline \multirow{2}{*}{ Properties } & ISO Standard & \multicolumn{4}{c}{ Paper Sample } \\
\cline { 3 - 6 } & & KW & BL & GR & COP \\
\hline Grammage $\left[\mathrm{g} / \mathrm{m}^{2}\right]$ & $536(2019)$ & $97.1 \pm 2.7$ & $118.9 \pm 2.5$ & $92.1 \pm 1.3$ & $79.5 \pm 0.7$ \\
Thickness $[\mathrm{mm}]$ & $534(2011)$ & $0.154 \pm 0.003$ & $0.208 \pm 0.004$ & $0.166 \pm 0.003$ & $0.102 \pm 0.002$ \\
Density $\left[\mathrm{kg} / \mathrm{m}^{3}\right]$ & $534(2011)$ & $630 \pm 11$ & $571 \pm 16$ & $556 \pm 11$ & $779 \pm 10$ \\
Specific volume $\left[\mathrm{cm}^{3} / \mathrm{g}\right]$ & $534(2011)$ & $1.588 \pm 0.027$ & $1.753 \pm 0.049$ & $1.799 \pm 0.035$ & $1.283 \pm 0.017$ \\
Moisture content $[\%]$ & $287(2018)$ & $5.7 \pm 0.1$ & $5.6 \pm 0.3$ & $5.5 \pm 0.4$ & $4.3 \pm 0.2$ \\
Ash content $[\%]$ & $1762(2019)$ & $2.42 \pm 0.03$ & $2.82 \pm 0.01$ & $3.68 \pm 0.13$ & $15.60 \pm 0.04$ \\
\hline
\end{tabular}




\subsubsection{Grammage}

The grammage of all investigated samples (KW, BL, GR, COP) complies with the production specifications (Table 7). The papers produced from IAPS (KW, BL, and GR) show a slightly higher variation in grammage $\left(2.7-1.3 \mathrm{~g} / \mathrm{m}^{2}\right)$, which can be attributed to the annual fibers and their slightly greater tendency to form bulkiness in the paper structure.

\subsubsection{Thickness}

The paper standard deviation of thickness of all the paper samples studied is within the acceptable limits, i.e., $0.002-0.004 \mathrm{~mm}$ (Table 7), which is normal for paper produced on the paper machine, i.e., $\mathrm{COP}$ has a standard deviation $0.002 \mathrm{~mm}$, which is, in comparison to handmade paper, more uniform.

\subsubsection{Density and Specific Volume}

BL has the highest density, $16 \mathrm{~kg} / \mathrm{m}^{3}$ and specific volume, $0.049 \mathrm{~cm}^{3} / \mathrm{g}$, deviation (Table 7), indicating some inhomogeneity of the papers. Papers made from IAPS are more voluminous than papers made from "conventional" cellulose fibers, i.e., trees (COP), and thus are more likely to exhibit some form of inhomogeneity in the form of weak dimensional stability.

\subsubsection{Moisture Content}

Moisture content is closely correlated with density and specific volume. As mentioned earlier, paper samples, i.e., KW, BL, and GR are more voluminous than COP. Consequently, the moisture content is higher for KW-GR (5.7-5.5\%) than for COP (4.3\%). The smaller the standard deviation of moisture content, the higher the dimensional stability of the paper sheet. Therefore, COP has the highest dimensional stability among the papers made from IAPS.

\subsubsection{Residue (Ash) Content}

The residue content (ash) determined by ashing at $525^{\circ} \mathrm{C}$ (Table 7) is significantly lower for IAPS, namely $2.42-3.68 \%$, which is reflected in a somewhat higher moisture content and the resulting voluminosity and poorer dimensional stability. Graphic papers can contain up to $30 \%$, in some cases even $40 \%$, of inorganic materials. The high proportion of inorganic fillers has a positive effect on the optical and printing properties, while the high proportion of inorganic fillers has a negative effect on the physical-mechanical properties. The particles of the inorganic fillers are placed at the joints of the cellulose fibers, reducing the possibility of possible fiber bonding and interlacing.

\subsection{Physical and Dynamic Mechanical Properties \\ 3.3.1. Tensile Properties}

Tensile strength, measured by the vertical tension method using a dynamometer, was carried out in the machine direction (MD) and cross direction (CD). Due to the predominant longitudinal orientation of the cellulose fibers in the paper, the tensile values of the paper in MD are generally about $2 \times$ higher because the interconnected cellulose fibers act like a chain. The results of the tensile strength measurements for MD and CD are shown in Table 8. The breaking strength is highest for $\mathrm{KW}$ at $81.99 \mathrm{~N}$ and is higher for two of the three papers made from IAPS, i.e., KW and BL, than for the pulp used to make COP $(59.36 \mathrm{~N})$. A slightly balanced relationship of the measured breaking forces is found in $\mathrm{CD}$, where the values are quite similar or in the same range. Again, GR is slightly more striking with $23.53 \mathrm{~N}$. In GR, the values of the breaking strength measurements indicate the use of a mixture of cellulose fibers with a higher proportion of wood fibers. As can be seen from the tensile strength measurements, in the case of GR they show the largest differences between the measurements in $\mathrm{MD}(21.25 \mathrm{MPa})$ and $\mathrm{CD}(9.32 \mathrm{MPa})$, i.e., the ratio is 2.28:1.00. This indicates a pronounced orientation of the fibers in $\mathrm{MD}$, since in the other cases of the studied papers $\mathrm{KW}, \mathrm{BL}$, and COP there is not such a pronounced difference 
in the MD:CD ratio, which requires a stronger isotropy of the papers at least in format printing, i.e., offset, inkjet, and digital printing. GR is, therefore, the paper with the weakest physical-mechanical properties and with a high anisotropy.

Table 8. Physical-mechanical properties.

\begin{tabular}{|c|c|c|c|c|c|c|c|c|c|c|}
\hline \multirow{2}{*}{ Sample } & \multicolumn{2}{|c|}{$\mathrm{F}_{15}[\mathrm{~N}]$} & \multicolumn{2}{|c|}{$\varepsilon[\%]$} & \multicolumn{2}{|c|}{$\mathrm{E}[\mathrm{MPa}]$} & \multicolumn{2}{|c|}{$\sigma[\mathrm{MPa}]$} & \multicolumn{2}{|c|}{$\mathrm{E}_{\max }[\mathrm{mJ}]$} \\
\hline & MD & CD & MD & CD & MD & CD & MD & CD & MD & CD \\
\hline KW & $82 \pm 6$ & $35 \pm 1$ & $2.18 \pm 0.30$ & $4.32 \pm 0.49$ & $4092 \pm 154$ & $1416 \pm 30$ & $35.49 \pm 2.40$ & $15.22 \pm 0.49$ & $215 \pm 0.04$ & $203 \pm 0.03$ \\
\hline BL & $69 \pm 4$ & $34 \pm 1$ & $1.22 \pm 0.07$ & $3.56 \pm 0.39$ & $3225 \pm 258$ & $1074 \pm 69$ & $21.75 \pm 1.38$ & $10.84 \pm 0.38$ & $89 \pm 0.01$ & $160 \pm 0.02$ \\
\hline GR & $54 \pm 4$ & $24 \pm 3$ & $1.22 \pm 0.16$ & $2.64 \pm 0.77$ & $3087 \pm 120$ & $981 \pm 63$ & $21.25 \pm 1,74$ & $9.32 \pm 1.33$ & $81 \pm 0.02$ & $72 \pm 0.03$ \\
\hline COP & $59 \pm 2$ & $32 \pm 1$ & $1.55 \pm 0.14$ & $5.07 \pm 0.37$ & $2988 \pm 52$ & $1960 \pm 36$ & $23.28 \pm 0.09$ & $21.28 \pm 0.69$ & $221 \pm 0.01$ & $106 \pm 0.02$ \\
\hline
\end{tabular}

$F_{15}$ is maximum force of $15 \mathrm{~mm}$ wide paper strip; $\varepsilon$ is tensile strain, $E$ is Young's modulus, $\sigma$ is tensile stress, $E_{\max }$ is energy at maximum force.

\subsubsection{Bending Clark Stiffness}

The bending stiffness or "readiness" of paper is the response of the paper to external deformation and is directly related to the quality and quantity of cellulose fibers incorporated into the product. Papers made from IAPS, i.e., cellulose fibers from annual plants that are shorter than wood fibers, are stiffer than papers made from wood fibers, and this includes softwood fibers. BL has the highest bending stiffness (3.97 Nmm), followed by KW (2.03 Nmm), GR (1.92 Nmm), while COP has $5.22 \times$ higher bending stiffness in MD and $4.35 \times$ in $\mathrm{CD}$ (Table 9, Figure 2).

Table 9. Bending stiffness.

\begin{tabular}{ccccc}
\hline \multirow{2}{*}{ Sample } & \multicolumn{2}{c}{ C [km/s] } & \multicolumn{2}{c}{ CS [Nmm] } \\
\cline { 2 - 5 } & MD & CD & MD & CD \\
\hline KW & $3.25 \pm 0.06$ & $2.12 \pm 0.02$ & $2.03 \pm 0.07$ & $0.86 \pm 0.02$ \\
BL & $3.04 \pm 0.14$ & $1.90 \pm 0.02$ & $3.97 \pm 0.37$ & $1.54 \pm 0.04$ \\
GR & $3.01 \pm 0.06$ & $1.84 \pm 0.01$ & $1.92 \pm 0.08$ & $0.71 \pm 0.01$ \\
COP & $3.32 \pm 0.04$ & $2.23 \pm 0.02$ & $0.76 \pm 0.02$ & $0.34 \pm 0.01$ \\
\hline
\end{tabular}

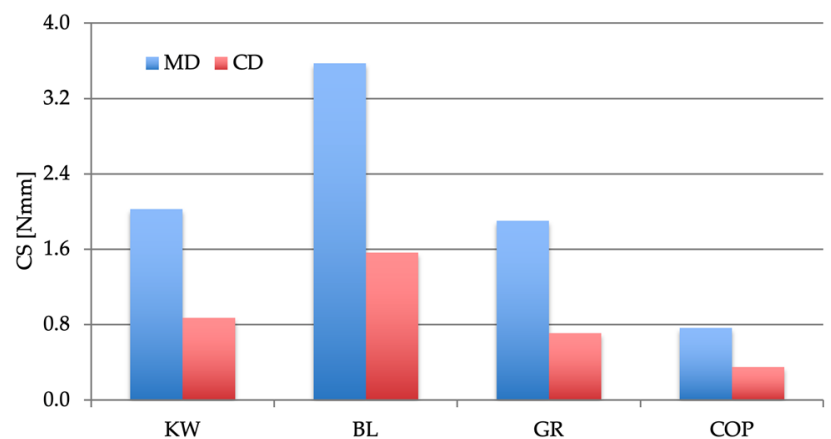

Figure 2. Clark bending stiffness.

In comparison, the linear correlation of the bending stiffness of the studied papers (Figure 3) is slightly lower in MD with $94.77 \%$ and in CD with $88.01 \%$. A high degree of linear correlation indicates the similarity of the studied papers, which gives the possibility of equivalent use of the studied papers. 


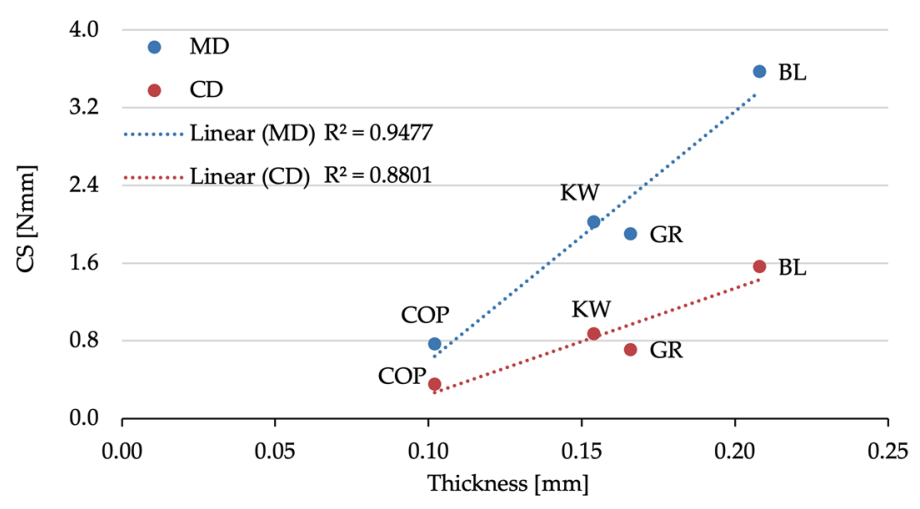

Figure 3. Linear dependence of Clark stiffness vs. paper thickness.

\subsubsection{Dynamic Mechanical (Viscoelastic) Properties}

Since the relaxation state of the strong cellulose crystallites does not change until the melting point, which is above the temperature of thermal decomposition [51], the relaxation transitions of the cellulose composite take place in the weak non-crystalline domains. There are three structural components responsible for the viscoelastic behavior of cellulose paper: lignin, hemicellulose (Table 4) and disordered parts of the macromolecular chains of cellulose, all of which represent the amorphous domains on the complex semicrystalline cellulose composite. These components are also responsible for the other structural properties that have an influence on viscoelasticity, such as the bonding and association of the cellulose fibers with the surrounding environmental factors (particularly moisture contact due to ambient relative humidity and temperature) [52,53], which are also mentioned further in this chapter of the paper. The viscoelastic curves, i.e., storage modulus $E^{\prime}$, loss modulus $E^{\prime \prime}$, damping factor $\tan \delta$, and dimension $L$ of the samples are shown in Figures 3-8, while the storage modulus values at $20^{\circ} \mathrm{C}$ and the temperature of the relaxation transitions $\mathrm{T}_{\mathrm{r}}$ are shown in Table 10. The storage modulus $\mathrm{E}^{\prime}$ (marked as green curves in Figures 6-9) is proportional to the energy stored by the material in one deformation cycle and represents the elastic response of the material. The loss modulus $\mathrm{E}^{\prime \prime}$ (marked as blue curves in Figures 6-9) is proportional to the energy (heat) dissipated by the material in one cycle and represents the viscous response of the material. The damping factor $\tan \delta$ (marked as brown curves in Figures 6-9), represents the ratio of the viscous to elastic response and is a measure of damping in the material. The length $\mathrm{L}$ (marked as pink curves in Figures 6-9), represents the change in dimensions of the sample (shrinking or expanding).

Table 10. The relaxation transition temperatures $T_{r}$ and storage modulus $E^{\prime}$.

\begin{tabular}{ccccc}
\hline \multirow{2}{*}{ Sample } & \multicolumn{3}{c}{ Relaxation Transition Temperature $\left(\mathrm{T}_{\mathbf{r}}\right)$ and Storage Modulus $\left(\mathbf{E}^{\prime}\right)$} \\
\cline { 2 - 5 } & \multicolumn{3}{c}{$\mathbf{T}_{\mathbf{r}}{ }^{*}\left[{ }^{\circ} \mathbf{C}\right]$} & $\mathbf{E}^{\prime}$ at 20 ${ }^{\circ} \mathbf{C}[\mathrm{GPa}]$ \\
\hline KW & 22.69 & & 191.60 & 1.970 \\
BL & & 24.41 & & 1.425 \\
GR & 37.46 & 32.08 & & 2.521 \\
COP & & 137.74 & 8.338 \\
\hline
\end{tabular}

${ }^{*} \mathrm{~T}_{\mathrm{r}}$ was taken as the inflection point of the storage modulus curve $\mathrm{E}^{\prime}$. 


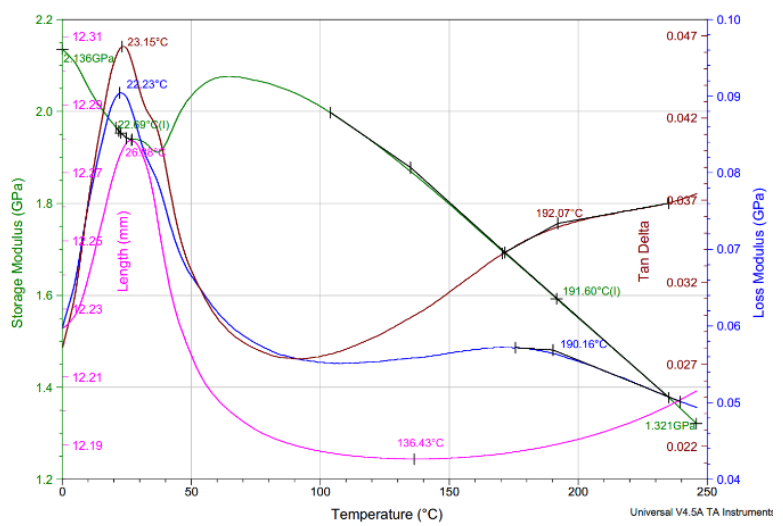

Figure 4. Storage modulus vs. temperature of KW.

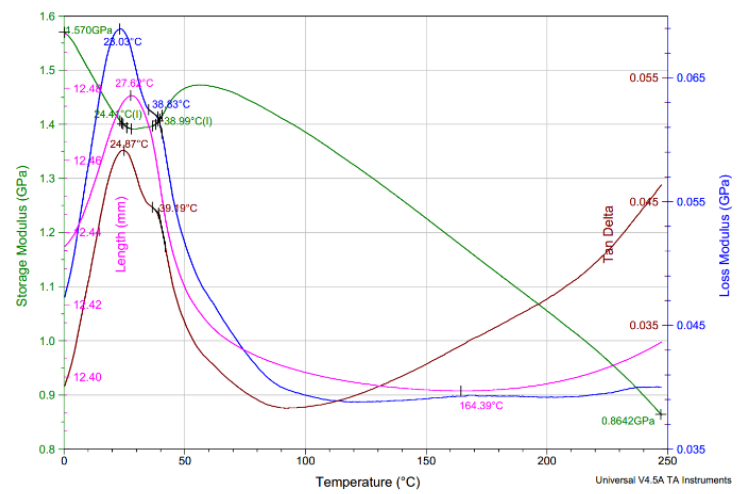

Figure 5. Storage modulus vs. temperature of BL.

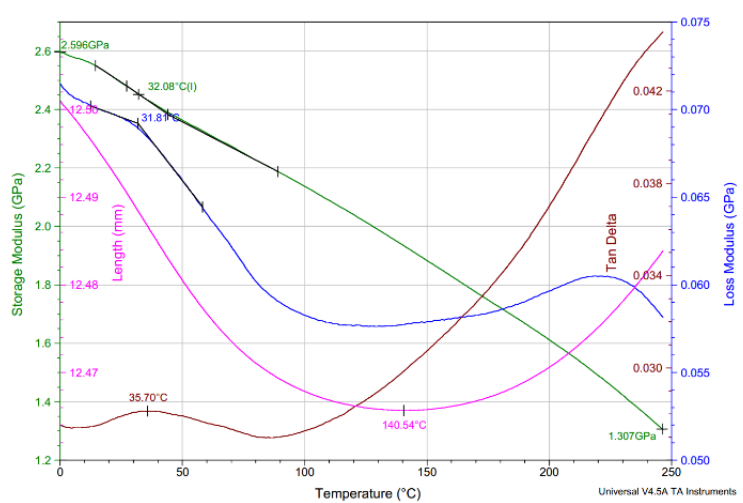

Figure 6. Storage modulus vs. temperature of GR.

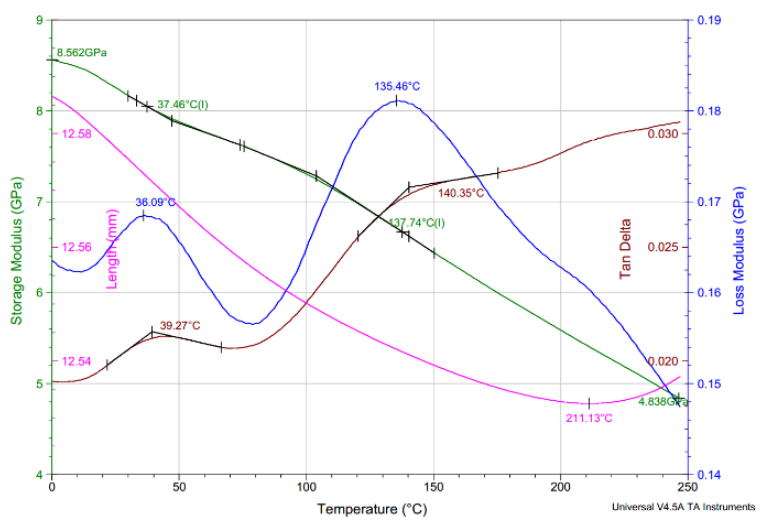

Figure 7. Storage modulus vs. temperature of COP. 


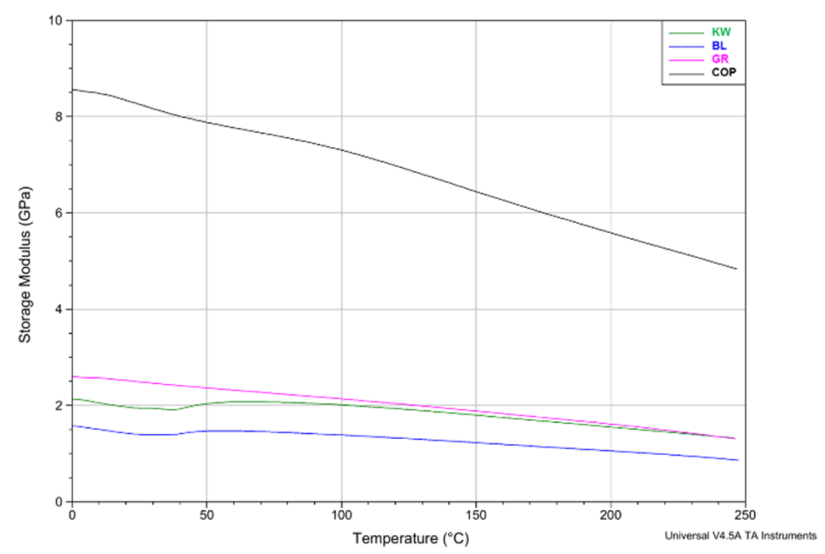

Figure 8. The comparison of storage modulus of KW, BL, GR, and COP.

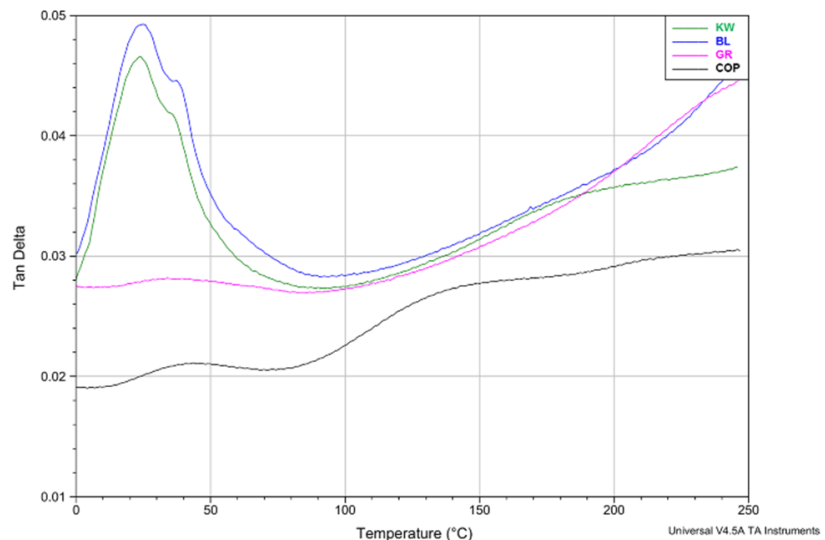

Figure 9. The comparison of damping factor of KW, BL, GR, and COP.

As shown in Figures 4-7, the temperature relaxation behavior of the cellulose structure is very complex because of its heterogeneity, and sometimes it is impossible to determine which component (or mixture thereof) is responsible for the overall behavior of the structure. The relaxation transitions are of different nature and occur in a wide temperature range below the temperature of thermal decomposition $[54,55]$. However, there are some features that stand out and can be discussed. All samples show a slow decrease in storage modulus $\mathrm{E}^{\prime}$ throughout the heated region, indicating the semi-crystalline structure of COP, as well as for KW-GR.

The viscoelastic curves of COP (Figure 7) show two relaxation regions indicated by the intensity of the $\tan \delta$ curves. The first region is located between 20 and $70{ }^{\circ} \mathrm{C}$ with $\mathrm{T}_{\mathrm{r}}=37.46^{\circ} \mathrm{C}$ and the larger, broader one between 80 and $170{ }^{\circ} \mathrm{C}$ with $\mathrm{T}_{\mathrm{r}}=137.74{ }^{\circ} \mathrm{C}$. The storage modulus, which stores the applied energy after the release of the sample and uses it to restore the deformation to the initial state, decreases from an initial $8.562 \mathrm{GPa}$ at $0{ }^{\circ} \mathrm{C}$ to $4.838 \mathrm{GPa}$ at $250{ }^{\circ} \mathrm{C}(43.5 \%)$. As mentioned, the decrease in modulus is slow and almost linear throughout the heated region. Up to room temperature $\left(\mathrm{ca} .20^{\circ} \mathrm{C}\right.$ ), the modulus decreases by $2.6 \%$. With the decrease in the elastic modulus and due to the applied heat, the segmental vibration of the structure segments occurs, which leads to the occurrence and increase in the mechanical loss modulus $\mathrm{E}^{\prime \prime}$. The maximum value of $\mathrm{E}^{\prime \prime}$ represents the beginning of the fluctuation of the molecular segments and consequently there is the scattering of the thermal energy (heat scattering of the sample). The scattering reaches its peak at 36.09 and $135.46^{\circ} \mathrm{C}$. The intensity of the molecular fluctuations is reflected in the height of the $\tan \delta$ curve and illustrates the internal friction of the structure. It peaks at $37.27^{\circ} \mathrm{C}$, followed by a peak at $140.35^{\circ} \mathrm{C}$. The sample stops shrinking at $211.13{ }^{\circ} \mathrm{C}$ and shrinks by $0.5 \%$. The final increase in length is the result of the thermal expansion of the 
structure due to the viscous component of the sample that has occurred and is shown for all samples.

Similar to COP, GR also shows a slow and linear decrease in its storage modulus throughout the heated region (Figure 6). The storage modulus drops from the initial $2.596 \mathrm{GPa}$ at $0{ }^{\circ} \mathrm{C}$ to $1.307 \mathrm{GPa}$ at $250{ }^{\circ} \mathrm{C}(49.6 \%)$. By room temperature, the modulus decreases by $2.9 \%$. The relaxation range is given between 10 and $80^{\circ} \mathrm{C}$, with the relaxation transition temperature at $32.08^{\circ} \mathrm{C}$, and above $90^{\circ} \mathrm{C}$. The sample stops shrinking at $140.54{ }^{\circ} \mathrm{C}$ and shrinks by $0.240 \%$.

KW and BL show similar viscoelastic behavior and deviate slightly from the behavior of GR and COP in the initial heated region up to $70{ }^{\circ} \mathrm{C}$ (Figures 4 and 5), where the storage modulus $\mathrm{E}^{\prime}$ and sample length initially decrease, then increase, and finally begin to gradually decrease. The decrease could be the result of the bound moisture, while the increase could result from the cellulose in the non-crystalline region of the cell wall, assuming a crystallized form to some extent. Thus, the storage modulus decreases from an initial $2.136 \mathrm{GPa}$ at $0{ }^{\circ} \mathrm{C}$ to $1.321 \mathrm{GPa}$ at $250{ }^{\circ} \mathrm{C}(38.2 \%)$, and from $1.570 \mathrm{GPa}$ at $0{ }^{\circ} \mathrm{C}$ to $0.8642 \mathrm{GPa}$ at $250{ }^{\circ} \mathrm{C}(45.0 \%)$ for $\mathrm{KW}$ and $\mathrm{BL}$, respectively. Up to room temperature, the modulus decreases by 7.8 and $9.2 \%$ for $\mathrm{KW}$ and $\mathrm{BL}$, respectively. The first given relaxation range can be considered as the main transition range for $\mathrm{KW}$ and $\mathrm{BL}$, since the dispersion of mechanical heat (loss modulus $\mathrm{E}^{\prime \prime}$ ) and the damping $(\tan \delta)$ of the structure are the strongest here. The relaxation transition temperatures for KW and BL are 22.69 and $24.41^{\circ} \mathrm{C}$, respectively.

The comparison of storage elasticity (Figure 8), which is an indicator of the bonding properties in the cellulose network, shows that papers made from IAPS (KW, BL, and GR) are less stiff compared to commercial office paper (COP). Thus, commercial office paper has a higher ability to store the stress energy, i.e., it behaves more elastically, i.e., with $\mathrm{E}^{\prime}=8.338 \mathrm{GPa}$ at $\mathrm{T}=20^{\circ} \mathrm{C}$. The papers of IAPS: $\mathrm{KW}, \mathrm{BL}$, and GR show much lower elasticity, i.e., their storage modulus decreases from $69.7 \%$ to up to $82.9 \%$ for BL and GR, respectively. BL shows the lowest elasticity, i.e., $\mathrm{E}^{\prime}=1.425 \mathrm{GPa}$, while GR behaves as the stiffest, i.e., $2.521 \mathrm{GPa}$. The reason for this difference in elasticity between the commercial office paper and papers from IAPS can be found in many factors. For example, the higher elasticity of COP could be the result of the following parameters and a mixture of them:

1. higher degree of intra- and inter-molecular interaction of cellulose chains, which can store the absorbed energy and lead to higher interconnectedness of cellulose fibers with a more closed network structure [55]; which is also the consequence of higher density and basis weight (see Section 3.2.);

2. higher degree of interlacing of the cellulose fibers with less hollow areas due to the higher proportion of thinner fibers of COP, as seen in SEM photos at higher magnifications (Table 6) and as a result of the thickness measurements (Table 7);

3. the higher overall degree of crystallinity of the cellulose structure;

4. the higher moisture content (Table 7), where the bonds of the intra- and inter-cellulose macromolecules are loosened and reduced due to the high affinity of the water and cellulose, i.e., the formation of new hydrogen bonds between the water molecules and the glucose monomers of the cellulose chains.

Comparison of the values of the damping factor $\operatorname{tg} \delta$ (Figure 9) shows that KW and BL are much more susceptible to the mobility of the molecular segments, resulting in greater macromolecular fluctuation and increased heat release, which can lead to microcracks in the structure. Therefore, aggressive mechanical loading during papermaking in the range of 10 to $50{ }^{\circ} \mathrm{C}$ is not recommended for $\mathrm{KW}$ and $\mathrm{BL}$.

Another factor that also specifies the viscoelastic behavior of the paper is the relaxation transition temperature, i.e., $\mathrm{T}_{\mathrm{r}}$. Papers from IAPS show lower $\mathrm{T}_{\mathrm{r}}\left(\mathrm{KW}=22.69^{\circ} \mathrm{C}\right.$, $\mathrm{BL}=24.41{ }^{\circ} \mathrm{C}, \mathrm{GR}=32.08{ }^{\circ} \mathrm{C}$, and $\mathrm{COP}=37.46$ and $137.74{ }^{\circ} \mathrm{C}$ ) compared to commercial office papers, as can be seen in Table 10. The reason can again be explained by the higher moisture content of KW, BL, and GR (Table 7), which leads to a decrease in intra- and inter-cellulose macromolecular bonds and makes the structure more susceptible to segment 
mobility under the influence of applied heat. The lower relaxation transition temperature $\mathrm{T}_{\mathrm{r}}$ may also be correlated with the hollower structure of KW, BL, and GR (Table 6), which is more prone to the mentioned segment mobility.

Some studies [56], even suggest that the relaxation transition temperature of paper depends mainly on the structural mobility of hemicellulose and lignin under the influence of ambient heat and moisture. As Olsson notes, lignin plays the main role in this phenomenon: its massive three-dimensional structure with large lateral methoxyl groups prevents its covalent self-crosslinking, while at the same time its large volume prevents its entanglement. This increases the mobility of its segments, leading to a decrease in the softening temperature. This observation could be the explanation for the lowest relaxation temperature $\mathrm{T}_{\mathrm{r}}$ of $\mathrm{KW}$, which contains the highest proportion of lignin and hemicellulose mixture compared to BL and GR (63.3\% in KW, $57 \%$ in BL, and $55 \%$ in GR). KW even contains the highest proportion of lignin ( $27 \%$ for $\mathrm{KW}, 22 \%$ for BL, and $19 \%$ for GR) (Table 4 ). Placet et al., further explains that the relaxation that occurs at lower temperatures is the consequences of the relaxation of hemicellulose, while at higher temperatures it belongs to the relaxation of lignin [57]. As studied in his research, ambient moisture shows different affinity to lignin and hemicellulose: the affinity for hemicellulose is high due to the presence of hydroxyl and carboxyl groups, which leads to an improvement in the flexibility of the cellulose network and a decrease in its stiffness. Thus, the relaxation takes place at lower temperatures. In contrast, the water affinity to lignin is low due to its massive molecular structure, which leads to relaxation occurring at higher temperatures.

\section{UV Impact on Dynamic Mechanical Properties}

After UV exposure (Figures 10-13 and Table 11), the elasticity of KW, BL, and GR at $20{ }^{\circ} \mathrm{C}$ increases significantly: by about $104 \%$ for $\mathrm{KW}, 23 \%$ for $\mathrm{BL}$, and $148 \%$ for the GR sample, while it decreases by $26.7 \%$ for the COP sample.

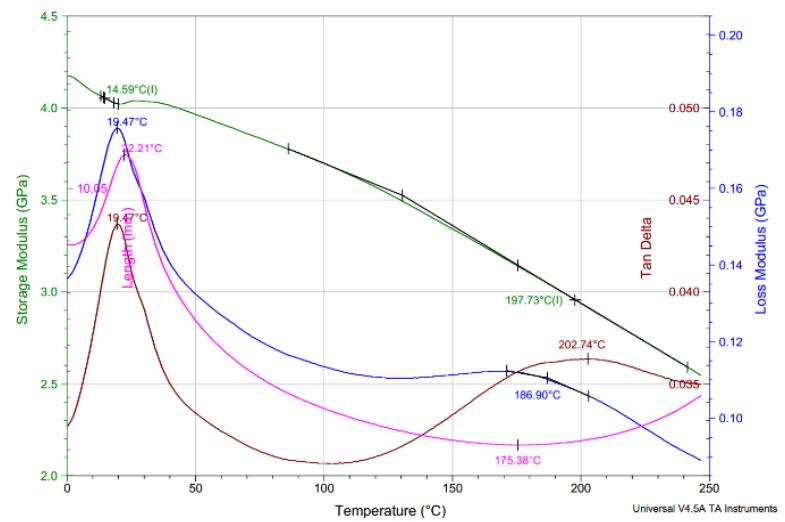

Figure 10. Storage modulus vs. temperature of KW.

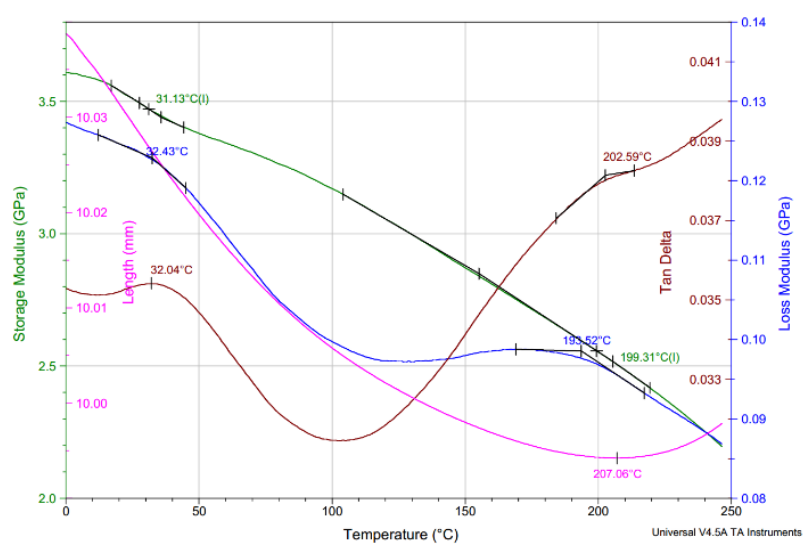

Figure 11. Storage modulus vs. temperature of BL. 


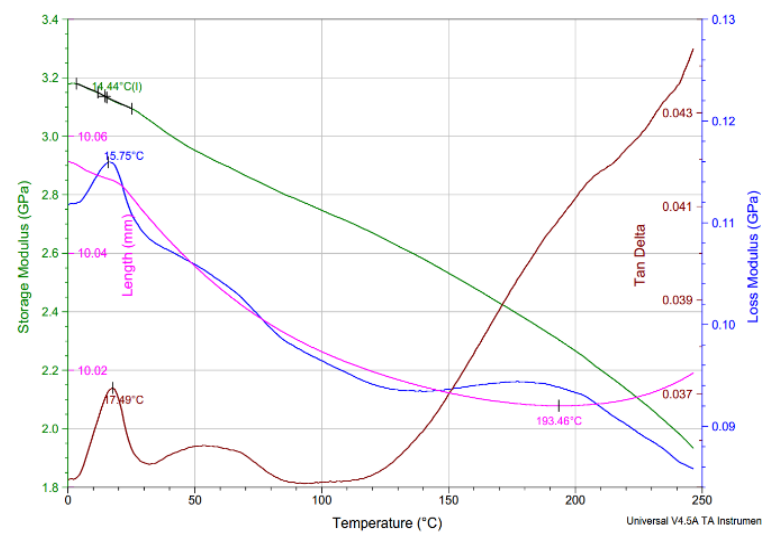

Figure 12. Storage modulus vs. temperature of GR.

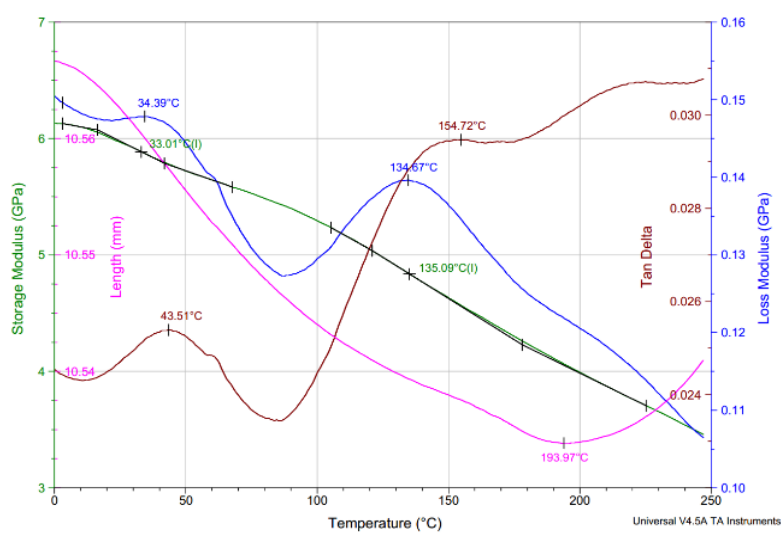

Figure 13. Storage modulus vs. temperature of COP.

Table 11. The relaxation transition temperatures $T_{r}$ and storage modulus $E^{\prime}$ of $K W, B L, G R$, and COP samples after UV exposure.

\begin{tabular}{|c|c|c|c|}
\hline \multirow{2}{*}{ Sample } & \multicolumn{3}{|c|}{ Relaxation Transition Temperature $\left(T_{r}\right)$ and Storage Modulus $\left(E^{\prime}\right)$} \\
\hline & & & $\mathrm{E}^{\prime}$ at $20^{\circ} \mathrm{C}$ [GPa] \\
\hline KW & 14.59 & 197.73 & 4.022 \\
\hline BL & 31.13 & 199.31 & 3.541 \\
\hline GR & \multicolumn{2}{|c|}{14.44} & 3.112 \\
\hline $\mathrm{COP}$ & 33.01 & 135.09 & 6.017 \\
\hline
\end{tabular}

${ }^{*} \mathrm{~T}_{\mathrm{r}}$ was taken as the inflection point of the storage modulus curve $\mathrm{E}^{\prime}$.

In general, UV light causes gradual degradation of paper, which has been shown for commercial office paper (COP). However, UV irradiation is the only type of cellulose degradation that affects only the amorphous regions, i.e., hemicellulose and lignin, and does not involve degradation of the crystalline fibril portion of the semi-crystalline cellulose structure. As suggested by Karlovits [58], the UV-exposed degraded amorphous domains form a more ordered structure, leading to covalent cross-linking through additional bonds. The more ordered structure is the result of the reduction in the "free volume", i.e., the molecules adjust their positions over time and consequently a tighter structure is formed, increasing the storage modulus $\mathrm{E}^{\prime}$. The cross-linking formed occurs in the wall of the cellulose fibers and in the fiber-fiber bonding surfaces [59]. The increase in elastic modulus of papers during natural and accelerated ageing is also suggested by Graminski [60]. The author adds that the increase in paper elasticity during ageing is probably also related to the crystallization processes and not only to the cross-linking reactions of the semicrystalline structure. 
As can be seen in Table 11, UV irradiation shifts the relaxation transition temperatures for KW, GR, and COP to the lower temperature and raises them for BL. The highest shift occurs for the GR sample $\left(\mathrm{T}_{\mathrm{r}}\right.$ decreases by $\left.8{ }^{\circ} \mathrm{C}\right)$, indicating the higher structural mobility and sliding of the macromolecules due to the applied heated oscillation stress.

\subsubsection{Linear Correlations between Structural, Physical, and Dynamic Properties}

By comparing the structural and physical-mechanical properties with the viscoelastic properties, such as storage modulus, i.e., elastic fraction, $\mathrm{E}^{\prime}$, and phase difference, $\tan \delta$, interesting linear correlations between the measured values can be observed (Figures 14-27). The viscoelastic behavior of the papers is mainly influenced by the moisture content, i.e., for the influence of the moisture content in the paper that it has on the elastic fraction, the linear correlation between the studied papers is $98.25 \%$ (Figure 22), while the influence on the phase difference is $71.58 \%$ (Figure 23). The lowest degree of linear correlation of the basic and physical-mechanical properties on the viscoelastic properties, i.e., mainly on the phase difference, has the Young's modulus, 29.02\% (Figure 27), the specific volume, $30.68 \%$ (Figure 21) and the paper density, $37.50 \%$ (Figure 19). In all cases of comparison of basic and physical-mechanical properties with viscoelastic properties, GR is closest to $\mathrm{COP}$, which directly indicates less use of cellulose fibers from invasive alien plants and more use of wood fibers in papermaking. We can also conclude that European goldenrod cellulose fibers (GR) are the closest to tree fibers in terms of basic and physical-mechanical properties and that they can be more integrated into papermaking for production purposes, which is an alternative to reducing the proportion of wood species in cellulose fibers. It is also encouraging that Japanese knotweed fibers (KW), one of the most widespread alien invasive plants, are relatively close to European goldenrod fibers (GR) in all cases of viscoelastic response, while acacia fibers (BL) are the most prominent and consequently the least suitable for the mechanical papermaking process.

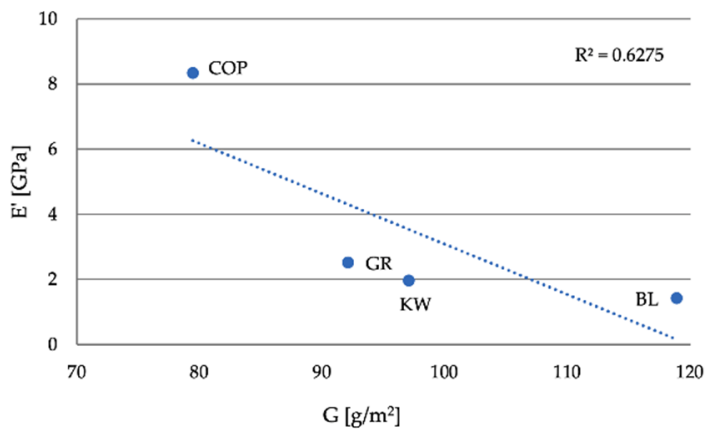

Figure 14. Storage modulus vs. Grammage.

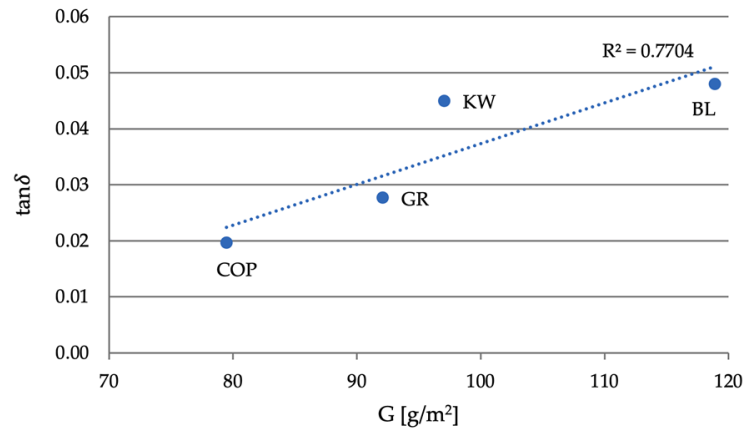

Figure 15. Energy loss vs. grammage. 


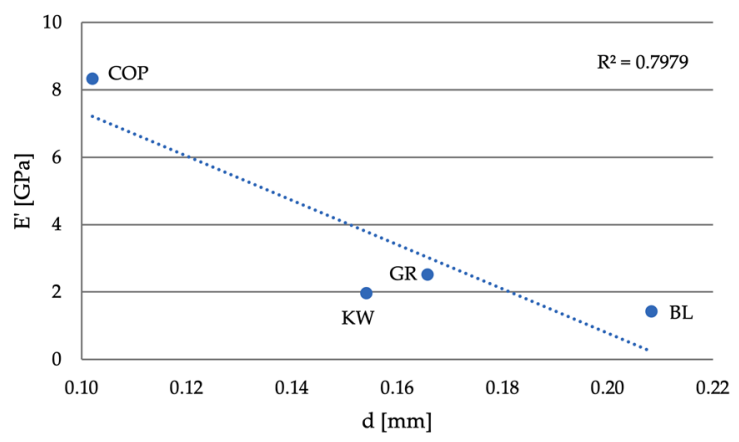

Figure 16. Storage modulus vs. thickness.

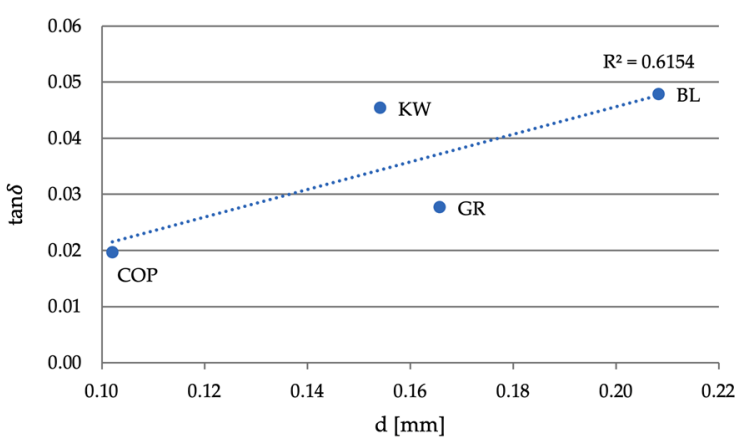

Figure 17. Energy loss vs. thickness.

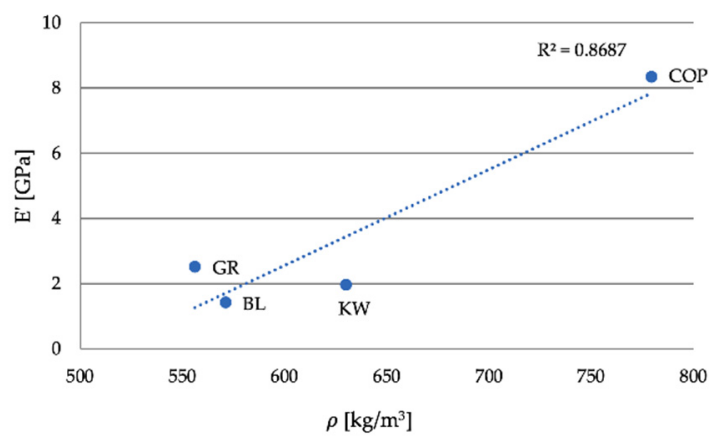

Figure 18. Storage modulus vs. density.

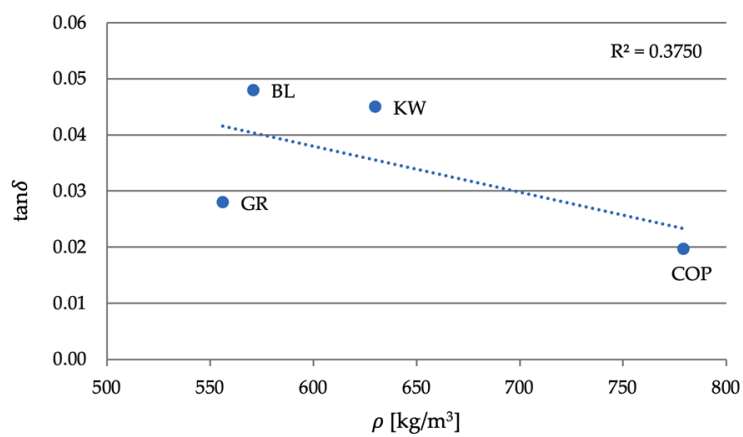

Figure 19. Energy loss vs. density. 


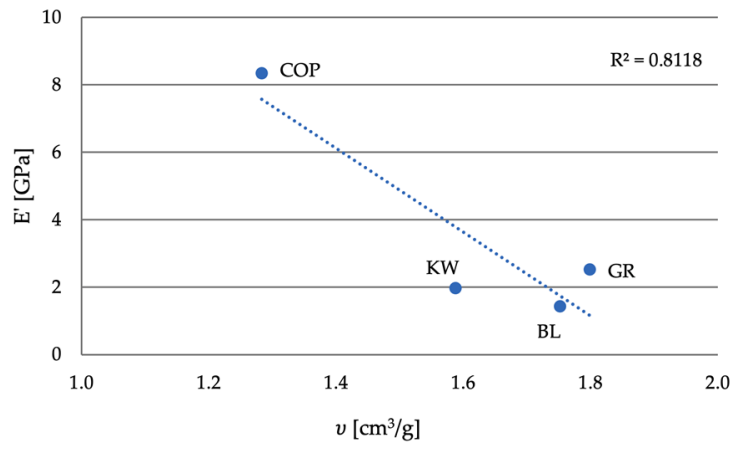

Figure 20. Storage modulus vs. specific volume.

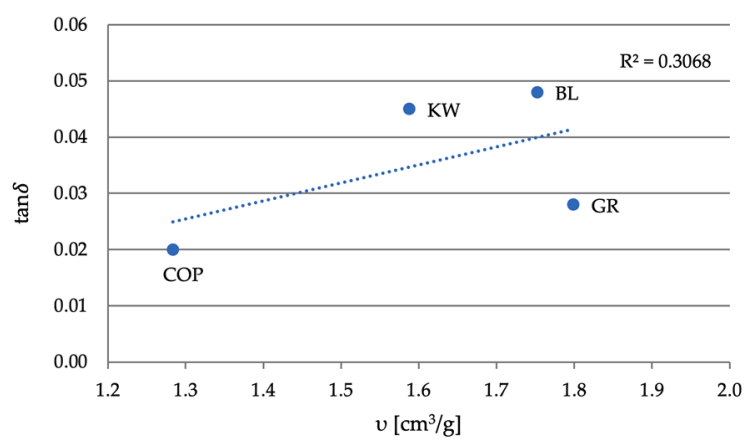

Figure 21. Energy loss vs. specific volume.

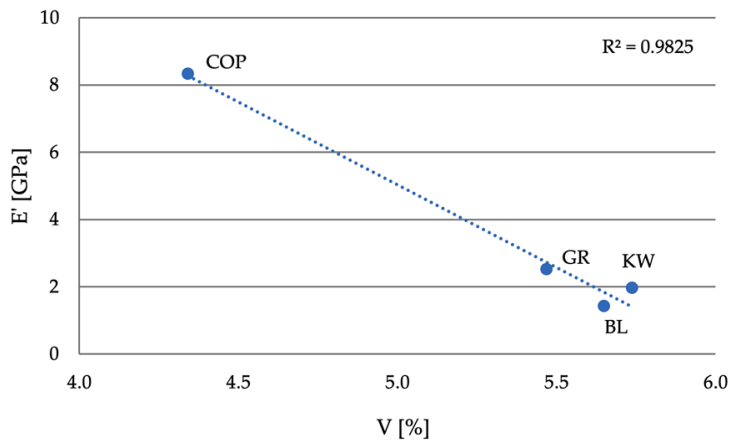

Figure 22. Storage modulus vs. Moisture content.

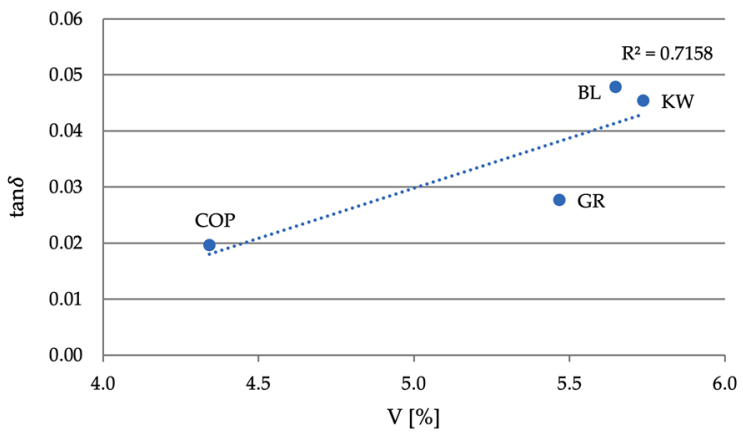

Figure 23. Energy loss vs. moisture content. 


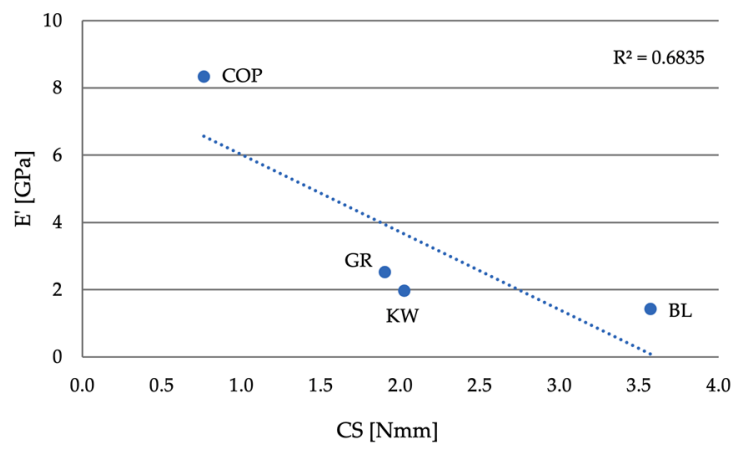

Figure 24. Storage modulus vs. Clark bending Stiffness.

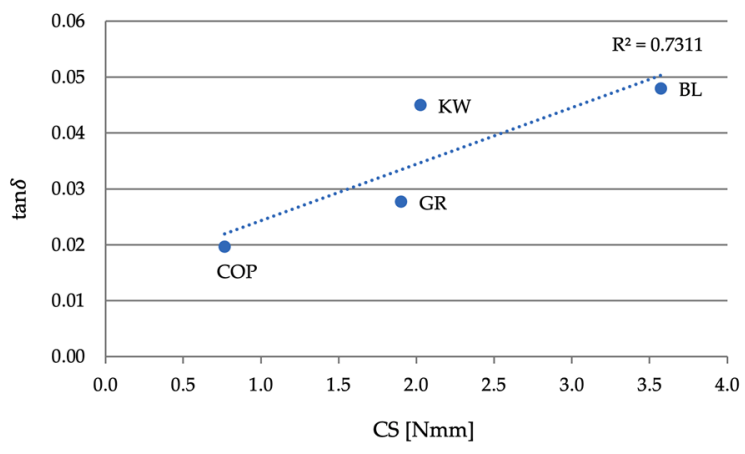

Figure 25. Energy loss vs. Clark bending Stiffness.

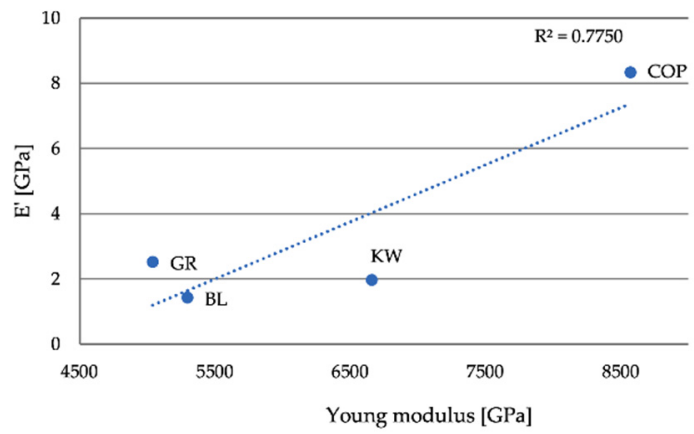

Figure 26. Storage modulus vs. Young modulus.

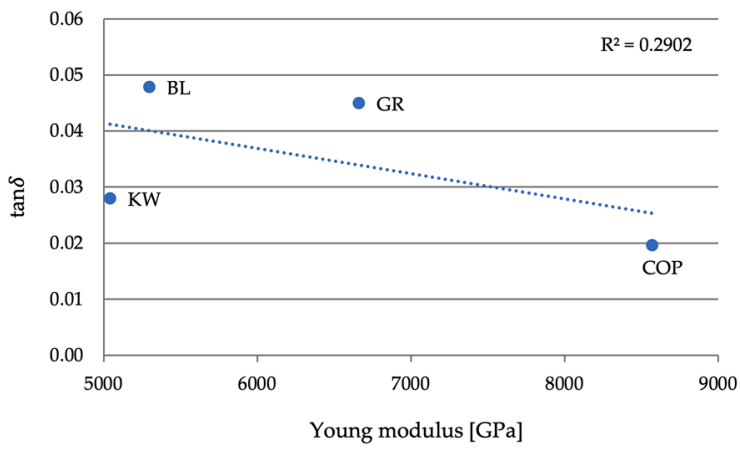

Figure 27. Energy loss vs. Young modulus.

\subsection{Colorimetric Measurements}

Figure 28 shows the course of spectrophotometric measurements of papers $\mathrm{KW}, \mathrm{BL}$, GR, and COP. The black print made on office paper (COP) is the darkest and has the lowest $\mathrm{L}^{*}$ value (26.80), while samples $\mathrm{KW}, \mathrm{BL}$, and GR have almost the same spectral values 
measured on black prints. This result was also expected since sample COP contains optical brighteners, and the prints give higher contrast. The presence of optical brighteners is evident from the graph, as the reflectance spectrum of COP exceeds the value of 100 in the blue region of the visible part of the spectrum.

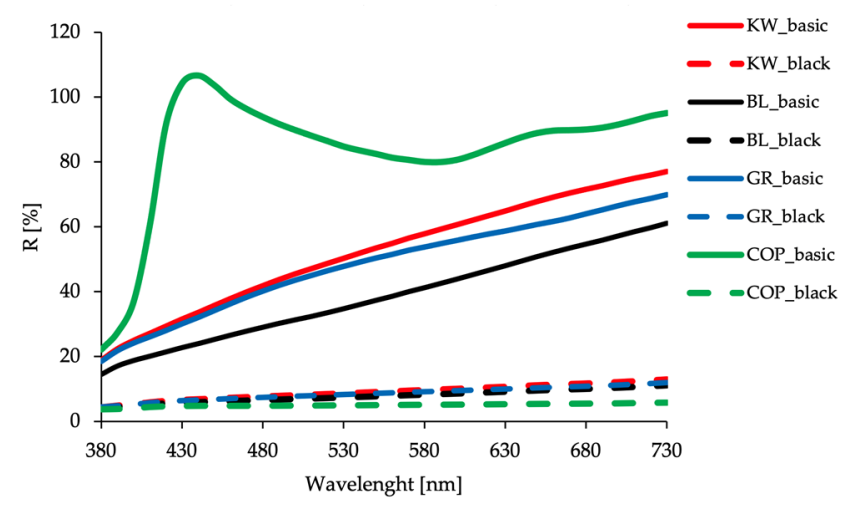

Figure 28. Measured spectral data of paper samples KW, BL, GR, and COP.

From the graph, it can be seen that paper BL is darkest with $L^{*}=68.56$, followed by GR with $\mathrm{L}^{*}=76.78, \mathrm{KW}$ with $\mathrm{L}^{*}=78.90$, and the lightest $\mathrm{COP}$ with $\mathrm{L}^{*}=93.33$.

UV Impact on Colorimetric Measurements

To determine the effect of the UV printer on the paper itself, we measured the CIELAB values on the base papers before and after passing through the printer. Table 12 shows that there was an imperceptible color difference for papers BL $\left(\Delta \mathrm{E}^{*} \mathrm{ab} 0.57\right)$ and $\mathrm{COP}\left(\Delta \mathrm{E}^{*} \mathrm{ab}\right.$ $0.73)$, while $\Delta E^{*}$ ab of papers $K W\left(\Delta E^{*} a b 2.1\right)$ and $G R\left(\Delta E^{*} a b 2.75\right)$ was small.

Table 12. Color difference- $\Delta \mathrm{E}^{*}$ ab between the basic paper and the basic paper exposed to the UV printer (one pass).

\begin{tabular}{ccccc}
\hline Paper & KW & BL & GR & COP \\
\hline$\Delta \mathrm{E}^{*} \mathrm{ab}$ & 2.10 & 0.57 & 2.75 & 0.73 \\
\hline
\end{tabular}

\section{Conclusions}

IAPS are a challenge in European ecosystems. However, once removed, they can be put to good use. In this study, papers were produced from three groups of IAPS from Slovenian habitats: Knotweed (mixture of Fallopia japonica, Fallopia sachalinensis, and Fallopia $\times$ bohemica), Goldenrod (Solidago canadensis, and Solidago gigantea), and Black Locust (Robinia pseudoacacia). Papers from IAPS were studied and compared with the commercial office paper.

According to the research hypotheses, the following conclusions can be drawn:

1. Papers made from cellulose fibers of IAPS are similar to papers made from conventional wood cellulose fibers, and hypothesis H1 is confirmed for the basic structural properties.

2. Papers made from IAPS cellulose fibers have a higher degree of anisotropy ( $\mathrm{H} 2$ is confirmed), and the elasticity of the papers differs compared to commercial office paper, as the IAPS papers have significantly lower elasticity compared to commercial office paper (H3 is confirmed), suggesting that the cross-linking of their structure is poorer;

3. Irradiation with UV light lowers the elasticity of the commercial office papers, while it has a positive effect on the papers made from IAPS, i.e., their elasticity increases after UV irradiation. Thus, the cross-linking of their structure is prolonged ( $\mathrm{H} 4$ is refuted); 
4. For printing purposes, the commercial office paper has the highest contrast of the surface printed with black. Due to the similar surface morphology, the IAPS papers are similar to office papers for printing (H5 to H7 are confirmed);

5. Paper produced from IAPS has the potential to be used for a similar purpose as commercial office paper, but with some limitations (H8 is partially confirmed):

- $\quad$ since the production process of collecting IAPS and making paper requires more time and energy, it is more expensive to produce;

- the lack of whiteness of paper made from IAPS is still the main reason why it is not mass produced, especially where the whiteness of the paper is of primary importance, i.e., for high resolution color printing;

- $\quad$ papers made from IAPS have the potential to be used for special corporate letters highlighting local environmental awareness in business, for advertising, ecological packaging, as art papers, and for environmental publications.

Author Contributions: Conceptualization, K.M. and B.B.P.; methodology, K.M., M.L., B.B.P., D.J., and M.S.; formal analysis, K.M., M.L., B.B.P., D.J., and M.S.; investigation, K.M., M.L., M.S., and D.J.; resources, B.B.P., K.M., and M.L.; Writing-Original draft preparation, B.B.P. and K.M.; WritingReview and editing, K.M., M.L., and B.B.P.; visualization, K.M., M.L., D.J., and M.S.; supervision, K.M., M.L., and B.B.P.; project administration, K.M. and M.L; funding acquisition, B.B.P. All authors have read and agreed to the published version of the manuscript.

Funding: The authors acknowledge the financial support from the APPLUSE project (UIA02-228), co-finances by the European Regional Development Fund through the Urban Innovative Action (UIA) initiative.

Institutional Review Board Statement: Not applicable.

Informed Consent Statement: Not applicable.

Data Availability Statement: Data are contained within the article.

Acknowledgments: The authors want to express their most sincere gratitude to PULP AND PAPER INSTITUTE, Slovenia (APPLUSE project partner; Ljubljana) for produced paper, e.g., KW-GR.

Conflicts of Interest: The authors declare no conflict of interest.

\section{References}

1. Marinšek, A.; Kutnar, L. Occurrence of IAPS in the floodplain forests along the Mura River in Slovenia. Period. Biol. 2008, 119, 251-260. [CrossRef]

2. Ficko, T. Ljubljana Circular Economy. Available online: https://www.uia-initiative.eu/en/uia-cities/ljubljana (accessed on 9 June 2020).

3. Cuixart, G. Uia-Initative.ue. Available online: https://www.uia-initiative.eu/en/news-events/applause-journal-2-new-systemtackle-invasive-alien-plant-species (accessed on 9 June 2020).

4. Applause Challenge. Available online: https://www.uia-initiative.eu/en/uia-cities/ljubljana (accessed on 12 June 2020).

5. Urban Innovative Actions Home Page. Available online: https://www.uia-initiative.eu/en/news/detection-and-mappingjapanese-knotweed-use-satellite-images (accessed on 13 January 2021).

6. Lavrič, G.; Pleša, T.; Mendizza, A.; Ropret, M.; Karlovits, I.; Gregor-Svetec, D. Printability characteristics of paper made from a Japanese knotweed. In Proceedings of the 9th International Symposium Graphic Engineering and Design (Grid 2018), Novi Sada, Serbia, 8-10 September 2018; pp. 99-102. [CrossRef]

7. Kim, H.G.; Lee, U.S.; Kwac, L.K.; Lee, S.O.; Kim, Y.S.; Shin, H.K. Electron beam irradiation isolates cellulose nanofiber from Korea "tall goldenrod" invasive alien plant pulp. Nanomaterials 2019, 9, 1358. [CrossRef]

8. Saikia, C.N.; Goswami, T.; Ali, F. Evaluation of pulp and paper making characteristics of certain fast-growing plants. Wood. Sci. Technol. 1997, 31, 467-475. [CrossRef]

9. Kapun, T.; Šinkovec, A.; Zule, J.; Skodlar, M.; Lavrič, G. Paper products made of paper from IAPS. In Proceedings of the 1st International Conference on Circular Packaging (CMC 2019), Ljubljana, Slovenia, 26-27 September 2019; pp. 197-204. [CrossRef]

10. Balogh, L. Japanese, giant and bohemian knotweed. In The Most Important Invasive Plants in Hungary; Botta-Dukát, Z., Balogh, L., Eds.; Institute of Ecology and Botany, Hungarian Academy of Sciences: Vácrátót, Hungary, 2008 ; pp. 13-33. ISBN 978-963-8391-42-1.

11. Strgulc-Krajšek, S.; Jogan, N. The genus Fallopia Adans. in Slovenia. Hladnikia 2011, 28, 17-40, ISSN:1318-2293. 
12. Gerber, E.; Krebs, C.; Murrell, C.; Moretti, M.; Rocklin, R.; Schaffner, U. Exotic invasive knotweeds (S1 spp.) negatively affect native plant and invertebrate assemblages in European riparian habitats. Biol. Conserv. 2008, 141, 646-654. [CrossRef]

13. Shan, B.; Cai, Y.Z.; Brooks, J.D.; Corke, H. Antibacterial properties of Polygonum cuspidatum roots and their major bioactive constituents. Food Chem. 2008, 109, 530-537. [CrossRef]

14. Peng, W.; Qin, R.; Li, X.; Zhou, H. Botany, phytochemistry, pharmacology, and potential application of Polygonum cuspidatum Sieb. et Zucc.: A review. J. Ethnopharmacol. 2013, 148, 729-745. [CrossRef]

15. Frantík, T.; Kovářová, M.; Koblihová, H.; Bartůňková, K.; Nývltová, Z.; Vosátka, M. Production of medically valuable stilbenes and emodin in knotweed. Ind. Crops Prod. 2013, 50, 237-243. [CrossRef]

16. Glavnik, V.; Vovk, I.; Albreht, A. High performance thin-layer chromatography-mass spectrometry of Japanese knotweed flavan-3-ols and proanthocyanidins on silica gel plates. J. Chromatogr. A 2017, 1482, 97-108. [CrossRef] [PubMed]

17. Yang, F.; Zhang, T.; Ito, Y. Large-scale separation of resveratrol, anthraglycoside A and anthraglycoside B from Polygonum cuspidatum Sieb. et Zucc by high-speed counter-current chromatography. J. Chromatogr. A 2001, 919, 443-448. [CrossRef]

18. Wang, D.G.; Liu, W.Y.; Chen, G.T. A simple method for the isolation and purification of resveratrol from Polygonum cuspidatum. J. Pharm. Anal. 2013, 3, 241-247. [CrossRef]

19. Gorjanc, M.; Savić, A.; Topalić-Trivunović, L.; Mozetič, M.; Vesel, A.; Grujić, D. Dyeing of plasma treated cotton and bamboo rayon with Fallopia japonica extract. Cellulose 2016, 23, 2221-2228. [CrossRef]

20. Werner, P.A.; Gross, R.S.; Bradbury, I.K. The Biology of Canadian Weeds: 45. Solidago canadensis L. Can. J. Plant. Sci. 1980, 60, 1393-1409. [CrossRef]

21. Weber, E.; Jakobs, G. Biological flora of central Europe: Solidago gigantea Aiton. Flora-Morphol. Distrib. Funct. Ecol. Plants 2005, 200, 109-118. [CrossRef]

22. De Groot, M.; Kleijn, D.; Jogan, N. Species groups occupying different trophic levels respond differently to the invasion of semi-natural vegetation by Solidago canadensis. Biol. Conserv. 2007, 136, 612-617. [CrossRef]

23. Abhilasha, D.; Quintana, N.; Vivanco, J.; Joshi, J. Do allelopathic compounds in invasive Solidago canadensis restrain the native European flora? J. Ecol. 2008, 96, 993-1001. [CrossRef]

24. CABI-Centre for Agriculture and Biosciences International (2018a): Solidago Gigantea (Giant Goldenrod), Datasheet, Invasive Species Compendium. Available online: https://www.cabi.org/isc/datasheet/50575\#tab1-nav (accessed on 27 August 2020).

25. CABI-Centre for Agriculture and Biosciences International (2018b): Solidago Canadensis (Canadian Goldenrod), Datasheet, Invasive Species Compendium. Available online: https://www.cabi.org/isc/datasheet/50599 (accessed on 27 August 2020).

26. Woźniak, D.; Ślusarczyk, S.; Domaradzki, K.; Dryś, A.; Matkowski, A. Comparison of Polyphenol Profile and Antimutagenic and Antioxidant Activities in Two Species Used as Source of Solidaginis herba-Goldenrod. Chem. Biodivers. 2018, 15, e1800023. [CrossRef] [PubMed]

27. Kołodziej, B. Antibacterial and antimutagenic activity of extracts aboveground parts of three Solidago species: Solidago virgaurea L., Solidago canadensis L. and Solidago gigantea Ait. J. Med. Plants Res. 2011, 5, 6770-6779. [CrossRef]

28. Anžlovar, S.; Koce, J.D. Antibacterial and antifungal activity of aqueous and organic extracts from indigenous and invasive species of goldenrod (Solidago spp.) grown in Slovenia. Phyton (Horn) 2014, 54, 135-147, ISSN: 0079-2047.

29. Zihare, L.; Blumberga, D. Insight into bioeconomy. Solidago canadensis as a valid resource. Brief review. Energy Procedia 2017, 128, 275-280. [CrossRef]

30. Sádlo, J.; Vítková, M.; Pergl, J.; Pyšek, P. Towards site-specific management of invasive alien trees based on the assessment of their impacts: The case of Robinia pseudoacacia. NeoBiota 2017, 35, 1-34. [CrossRef]

31. Vítková, M.; Müllerová, J.; Sádlo, J.; Pergl, J.; Pyšek, P. Black locust (Robinia pseudoacacia) beloved and despised: A story of an invasive tree in Central Europe. For. Ecol. Manag. 2017, 384, 287-302. [CrossRef] [PubMed]

32. Veitch, N.C.; Elliott, P.C.; Kite, G.C.; Lewis, G.P. Flavonoid glycosides of the black locust tree, Robinia pseudoacacia (Leguminosae). Phytochemistry 2010, 71, 479-486. [CrossRef]

33. Nicolescu, V.N.; Hernea, C.; Bakti, B.; Keserú, Z.; Antal, B.; Rédei, K. Black locust (Robinia pseudoacacia L.) as a multi-purpose tree species in Hungary and Romania: A review. J. For. Res. 2018, 29, 1449-1463. [CrossRef]

34. Mantovani, D.; Veste, M.; Boldt-Burisch, K.; Fritsch, S.; Koning, L.A.; Freese, D. Carbon allocation, nodulation, and biological nitrogen fixation of black locust (Robinia pseudoacacia L.) under soil water limitation. Ann. For. Res. 2015, 58, 259-274. [CrossRef]

35. Papaioannou, A.; Chatzistathis, T.; Papaioannou, E.; Papadopoulos, G. Robinia pseudoacacia as a valuable invasive species for the restoration of degraded croplands. Catena 2016, 137, 310-317. [CrossRef]

36. Kleinbauer, I.; Dullinger, S.; Peterseil, J.; Essl, F. Climate change might drive the invasive tree Robinia pseudacacia into nature reserves and endangered habitats. Biol. Conserv. 2010, 143, 382-390. [CrossRef]

37. Vítková, M.; Tonika, J.; Müllerová, J. Black locust: Successful invader of a wide range of soil conditions. Sci. Total Environ. 2015, 505, 315-328. [CrossRef] [PubMed]

38. Lazzaro, L.; Mazza, G.; Errico, G.; Fabiani, A.; Giuliani, C.; Inghilesi, A.F.; Roversi, P.F. How ecosystems change following invasion by Robinia pseudoacacia: Insights from soil chemical properties and soil microbial, nematode, microarthropod and plant communities. Sci. Total Environ. 2018, 622, 1509-1518. [CrossRef] [PubMed]

39. Snyder, L.U.; Luginbuhl, J.M.; Mueller, J.P.; Conrad, A.P.; Turner, K.E. Intake, digestibility and nitrogen utilization of Robinia pseudoacacia foliage fed to growing goat wethers. Small Rumin. Res. 2007, 71, 179-193. [CrossRef] 
40. Yang, S.; Li, G.; Zhao, Z.; Feng, M.; Fu, J.; Huang, Z.; Song, M.; Lin, S. The Taishan Robinia pseudoacacia polysaccharides enhance immune effects of rabbit haemorrhagic disease virus inactivated vaccines. Microb. Pathog. 2017, 112, 70-75. [CrossRef] [PubMed]

41. Bhalla, P.; Bajpai, V.K. Chemical composition and antibacterial action of Robinia pseudoacacia L. flower essential oil on membrane permeability of foodborne pathogens. J. Essent. Oil-Bear. Plants 2017, 20, 632-645. [CrossRef]

42. SEM, Geochemical Instrumentation and Analysis. Available online: https://serc.carleton.edu/research_education/ geochemsheets/techniques/SEM.html (accessed on 25 November 2020).

43. ISO 536: Paper and Board—Determination of Grammage, ISO: Geneve, Switzerland, 2019; 8p, ICS 85.060.

44. ISO 534: Paper and Board-Determination of Thickness-Density and Specific Volume; ISO: Geneve, Switzerland, 2011; 13p, ICS 85.060.

45. ISO 287: Paper and Board-Determination of Moisture Content of a Lot-Oven Drying Method; ISO: Geneve, Switzerland, 2017; 10p, ICS 85.060.

46. ISO 1762: Paper, Board, Pulps and Cellulose Nanomaterials—Determination of Residue (Ash Content) on Ignition at $525^{\circ} \mathrm{C}$; ISO: Geneve, Switzerland, 2019; 9p, ICS 85.040.

47. ISO 1924-2: Paper and Board-Determination of Tensile Properties-Part. 2: Constant Rate of Elongation Method (20 mm/min); ISO: Geneve, Switzerland, 2008; 12p, ICS 85.060.

48. Okomori, K.; Enomae, T.; Onabe, F. Evaluation and control of coated paper stiffness. Jpn. Tappi J. 1997, 51, 635-644. [CrossRef]

49. ISO 12040: Graphic Technology_Prints and Printing Inks_-Assessment of Light Fastness Using Filtered Xenon Arc Light; ISO: Geneve, Switzerland, 1997; 5p, ICS 87.080.

50. ApexJet UV Printer, Microtec Technology Company. Available online: https://www.apex-jet.com/products/DTG-TextilePrinter. htm (accessed on 10 December 2020).

51. Ioelovich, M. Isophase Transitions of Cellulose-A Short Review. Athens J. Sci. 2016, 3, 309-322. [CrossRef]

52. Perkins, R.W., Jr. Handbook of Physical Testing of Paper: Volume 1, 2nd ed.; Mark, R.E., Habeger, C., Borch, J., Bruce-Lyne, M., Eds.; Marcel Dekker, Inc.: New York, NY, USA, 2001; pp. 22-26. ISBN 0-8247-0498-3.

53. Roylance, D.; McElroy, P.; McGarry, F. Viscoelastic properties of paper. Fibre Sci. Technol. 1980, 13, 411-421. [CrossRef]

54. Kaimin, I.; Karlivan, V.; Ioelovich, M. Temperature transitions of cellulose and their dependence on low molecular substances. News Latv. Acad. Sci. 1979, 8, 112-123, ISSN 1407-009X.

55. Börjesson, M. Radiation Crosslinking of Cellulose Fibres to Obtain Rigid Lightweight Paperboard. Licentiate Thesis, Chalmers University of Technology, Department of Chemical and Biological Engineering, Gothenburg, Sweden, 2013; pp. 13-15, ISSN 1652-943X.

56. Olsson, A.M.; Salmkn, L. The effect of lignin structure on the viscoelastic properties of wood. Nord. Pulp Paper Res. J. 1997, 12, 140-144. [CrossRef]

57. Placet, V.; Passard, P.; Perré, P. Viscoelastic properties of wood across the grain measured under water-saturated conditions up to $135^{\circ} \mathrm{C}$ : Evidence of thermal degradation. J. Mater. Sci. 2008, 43, 3210-3217. [CrossRef]

58. Karlovits, M.; Gregor-Svetec, D. Durability of Cellulose and Synthetic Papers Exposed to Various Methods of Accelerated Ageing. Acta Polytech. Hung. 2012, 9, 81-100. [CrossRef]

59. Fellers, C.; Iversen, T.; Lindström, T.; Nilsson, T.; Rigdahl, M. Ageing/Degradation of Paper: A Literature Survey; Swedish Pulp and Paper Research Institute: Stockholm, Sweden, 1989; pp. 11-18, ISSN 0284-5636.

60. Graminski, E.L. The Stress-strain Behavior of Accelerated and Naturally Aged Papers. Tappi 1970, 53, 406-410, ISSN 00398241. 